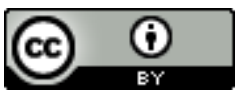

Esta obra está sob o direito de Licença Creative Commons Atribuição 4.0 Internacional.

\title{
ASPECTOS BIOECOLÓGICOS E QUÍMICOS DE PACHYCORIS TORRIDUS (SCOPOLI, 1772) (HEMIPTERA: SCUTELLERIDAE) NA HERBIVORIA DE JATROPHA CURCAS (LINNAEUS) (EUPHORBIACEAE)
}

\author{
Andrea Marques Vanderlei Fregadolli ${ }^{1}$ \\ Paulo Vanderlei Ferreira ${ }^{2}$ \\ Fábio Luiz Fregadolli \\ Edjane Vieira Pires ${ }^{4}$ \\ Antônio Euzébio Goulart Sant' Ana \\ Laurício Endres ${ }^{6}$
}

\section{RESUMO}

O presente trabalho visa avaliar aspectos bioecológicos e químicos de $\mathrm{P}$. torridus na herbivoria. Trata-se de uma revisão de literatura, não sistemática. A varreadura dos artigos científicos para elaboração da revisão foi realizada nas bases eletrônciacas Scielo, ScienciDirect, BVS, Scopus e Google Acadêmico. A espécie Jatropha curcas (Linnaeus) (Euphorbiaceae) produz matéria-prima para obtenção de biodiesel. O seu alto conteúdo de óleo e baixo custo de produção tornam-a uma cultura altamente promissora sob o ponto de vista econômico e social, uma vez que se desenvolve em pequenas propriedades, com a mão-de-obra familiar disponível. Por isso, é cultivada em vários países, dentre eles: China, Índia, Filipinas, Malásia, Nicarágua, Honduras e Brasil. Pachycoris torridus (Scopoli, 1772) (Hemiptera: Scutelleridae) é o único representante da família Scutelleridae de impacto agrícola no Brasil. Esse percevejo é a principal praga da Jatropha curcas (Linnaeus) (Euphorbiaceae), a qual produz matéria-prima para obtenção de biodiesel. de J. curcas.

Palavras-chave: Pinhão-manso; Eficiência fotoquímica; Percevejo do pinhão-manso; Comportamento reprodutivo.

\footnotetext{
${ }^{1}$ Graduada em Farmácia, Educação Física e Análise e Desenvolvimento de Sistemas. Mestre em Modelagem Computacional de Conhecimento pele Universidade Federal de Alagoas (UFAL, 2011). Doutora em Química e Biotecnologia (UFAL).

2 Graduado em Agronomia pela Universidade Federal de Alagoas (UFAL). Mestrado em Agronomia pela Universidade de São Paulo (USP). Doutorado em Agronomia (USP).

${ }^{3}$ Possui graduação em Zootecnia pela Universidade Estadual de Maringá (1996), mestrado em Zootecnia pela Universidade Estadual de Maringá (2000) e doutorado em Zootecnia pela Universidade Estadual Paulista Júlio de Mesquita Filho (2004).

${ }^{4}$ Possui graduação em Química Licenciatura pela Universidade Federal de Alagoas (2005), mestrado em Química e Biotecnologia pela Universidade Federal de Alagoas (2008) e doutorado em Química e Biotecnologia pela Universidade Federal de Alagoas (2013).

${ }^{5}$ Possui graduação em Farmácia e Bioquímica pela Universidade Federal de Minas Gerais (1975) e doutorado em Química pela Universidade Federal de Minas Gerais (1984).

${ }^{6}$ Possui graduação em Agronomia pela Universidade Federal de Pelotas (1993), mestrado em Ciências Agrárias (Fisiologia Vegetal) pela Universidade Federal de Viçosa (1996) e doutorado em Ciências pela Universidade de São Paulo (2001).
} 


\section{INTRODUÇÃO}

A espécie Jatropha curcas (Linnaeus) (Euphorbiaceae) produz matéria-prima para obtenção de biodiesel. O seu alto conteúdo de óleo e baixo custo de produção tornam-a uma cultura altamente promissora sob o ponto de vista econômico e social, uma vez que se desenvolve em pequenas propriedades, com a mão-de-obra familiar disponível. Por isso, é cultivada em vários países, dentre eles: China, Índia, Filipinas, Malásia, Nicarágua, Honduras e Brasil (SATURNINO et al., 2005).

Os desafios de abastecimento de energia também podem ser enfrentados com o líquido biocombustível, que é produzido facilmente pelo pinhão-manso (ACHTEN et al., 2008), nome o qual a $J$. curcas é conhecida popularmente (DRUMMOND et al., 1984).

Doenças e insetos-praga que acometem a espécie $J$. curcas precisam ser investigados devido as contradições dos pesquisadores quanto a resistência dessa cultura (ALBUQUERQUE et al., 2008). Sabe-se que o percevejo da espécie Pachycoris torridus (Scopoli, 1772) (Hemiptera: Scutelleridae) é a principal praga da $J$. curcas. A herbivoria realizada em seus frutos, por ninfas e adultos dessa espécie de percevejo afeta a formação do endosperma e promove queda da flor, bem como chochamento das sementes em função da sucção de frutos imaturos. Em consequência, escurecimento, deformidade, queda dos mesmos (aborto prematuro) e/ou diminuição de seu tamanho, afetando, assim, a produção de óleo, a qual pode ser reduzida até 50\% (AMERICA, 2007; RODRIGUES et al., 2011; GABRIEL; FRANCO, 2012).

Pachycoris torridus é o único representante da família Scutelleridae de impacto agrícola no Brasil (MONTE, 1937; GALLO et al., 2002). Apresenta um aparelho bucal sugador desde ninfa, que se torna maior e mais resistente ao atingir a fase adulta, a ponto de sugar qualquer parte da planta, mas sua maior preferência, na fase adulta, é o fruto verde ou maduro da $J$. curcas, quando presente. (AMERICA, 2007; NAVA, DELMAR, 2009; BROGLIO-MICHELETTI et al., 2010; RODRIGUES et al., 2011; GABRIEL; FRANCO, 2012). Por isso, investigar as injúrias causadas por $P$. torridus em mudas de $J$. curcas, visa avaliar a resistência dessa cultura nos estádios inicias.

Segundo Rodrigues et al. (2011) o maior dano em frutos e sementes de $J$. curcas é provocado por fêmeas da espécie $P$. torridus, o que pode ser explicado pela sua necessidade de adquirir reservas nutricionais para o desenvolvimento de óvulos e proteção das posturas. Em mudas 
de $J$. curcas, o maior dano também pode ser ocasionado por fêmeas, devido a mesma necessidade. $O$ processo fotossintético pode ser prejudicado, consequentemente menor desenvolvimento da planta, seguido posteriormente de redução da produção de óleo.

Espécies do gênero Pachycoris são semelhantes (GABRIEL; FRANCO, 2012) e essa aparência similar confunde pesquisadores, por isso o percevejo $P$. torridus foi descrito oito vezes como sendo uma nova espécie (COSTA LIMA, 1940). O colorido de seu corpo é bem variado, assim como o padrão de suas manchas situadas no pronoto e escutelo (MONTE, 1937, GALLO et al., 1988). Pachycoris klugii (Burmeister, 1835) (Hemiptera: Scutelleridae) também possui coloração aposemática, apresentando-se em verde metálico brilhante com manchas amarelas, laranjas ou vermelhas; tal percevejo foi registrado erroneamente como sendo o da espécie P. torridus (PEREDO, 2002).

É extremamente necessário um estudo dos aspectos bioecológicos, com ênfase nos comportamentos de corte e cópula, bem como da capacidade de oviposição de $P$. torridus, que complemente as pesquisas de Santos et al. (2005), Rodrigues I et al. (2011), Gabriel et al. (2012) e Borges Filho et al. (2013), que tratam dos aspectos biológicos e reprodutivo dessa espécie. Essas informações são cruciais na busca da composição feromonal, a fim de adotar medidas no controle comportamental dessa praga.

A comunicação química dos insetos se faz por um grande número de substâncias (semioquímicos) com estruturas químicas variadas. Indivíduos da mesma espécie se comunicam através de semioquímicos do tipo feromônios (PARK, 2002). Tais compostos fazem parte de um universo bastante amplo dessa comunicação, por isso o controle comportamental através de feromônios vem conquistando o mercado.

Cada espécie possui o seu próprio código de comunicação baseado nas diferenças estruturais dos compostos, que permite criar uma linguagem entendida apenas por insetos da mesma espécie (BJOSTAD, 1998). Os sinais químicos, emitidos por eles, desempenham funções vitais, como: defesa, seleção de plantas hospedeiras, localização de presas, corte, acasalamento e escolha de locais para oviposição (TEGONI et al., 2004).

As ações de controle comportamental através do uso de feromônios fazem parte de um modelo preconizado para a agricultura do futuro, por ser uma técnica que tem alta especificidade, onde nenhum resíduo químico é depositado no meio ambiente, 
sendo assim não há efeito deletério às espécies animais e vegetais (ZARBIN; RODRIGUES; COSTA LIMA, 2009).

Este trabalho interdisciplinar objetivou explorar aspectos relacionados

\section{METODOLOGIA}

Trata-se de uma pesquisa secundária, do tipo revisão tradicional, não sistemática. A varreadura dos artigos

\section{RESULTADOS E DISCUSSÃO}

Após análise dos documentos foi desenvolvida 5 categorias temáticas e 11 subcategorias, a saber: Jatropha curcas (Linnaeus) (Euphorbiaceae) (Publicações sobre Jatropha curcas), Eficiência fotoquímica do processo fotossintético, Pachycoris torridus (Scopoli, 1772) (Hemiptera: Scutelleridae) (morfologia, padrões cromáticos, glândulas, reprodução e ciclo biológico, desenvolvimento embrionário, distribuição geográfica de percevejos (insetos-praga), corte e cópula dos percevejos), Programa de Manejo Integrado de Pragas (MIP), semioquímicos (feromônios, feromônios de alarme e compostos cuticulares).

\section{Jatropha curcas (Linnaeus) (Euphorbiaceae) \\ O gênero Jatropha, pertencente à} família Euphorbiaceae, segunda mais com a Agronomia, Biologia, Bioecologia e Ecologia Química, com ênfase nessas duas últimas ciências.

científicos para elaboração da revisão foi realizada nas bases eletrônciacas Scielo, ScienciDirect, BVS, Scopus e Google Acadêmico.

representativa da Caatinga em número de espécies, superada apenas por Leguminosae (SAMPAIO, 1995). É constituído por 175 espécies distribuídas pela América Tropical, Ásia e África (WEBSTER, 1994; AUGUSTUS; JAYABALA; SEILERB, 2002), podendo ser monóicas, dióicas, hemafroditas ou raramente poligâmicas (GALLINDO, 1985), atingindo dois a três metros de altura (ARRUDA et al., 2004). Vários grupos de polinizadores visitam as espécies desse gênero (WEBSTER, 1994).

A família Euphorbiaceae foi considerada a terceira família com maior número em espécies, cerca de 8000, distribuída principalmente em regiões tropicais. Representada por 317 gêneros, presentes em vários biomas. Na Caatinga, foram registradas 73 espécies, das quais 17 endêmicas, superada apenas por Fabaceae e Convolvulaceae (WEBSTER, 1994; GIULIETTI et al., 2006). 
A espécie Jatropha curcas é popularmente conhecida como pinhão manso, pinhão do Paraguai, purgueira, pinha-de-purga, grão-de-maluco, pinhãode-cerca, pinhão-bravo, figo-do-inferno, pinhão-das-barbadas (DRUMMOND et al., 1984). Essa planta é perene, de fácil cultivo (SATURNINO et al., 2005).

O pihão-manso é considerado uma alternativa para enfrentar os desafios de abastecimento de energia, seu óleo pode ser facilmente convertido em líquido biocombustível (ACHTEN et al., 2008), que atende aos padrões da Europa e Estados Unidos (AZAM; WARIS; NAHAR, 2005; TIWARI; KUMAR; RAHEMAN, 2007).

O semiárido nordestino possui características climáticas (balanço hídrico, insolação, precipitações e temperatura) diferenciadas das demais regiões do Brasil. Essas características climáticas fazem com que o pinhão-manso seja considerado uma opção agrícola, por ser uma espécie nativa e com forte resistência à seca (ARRUDA et al., 2004), além de apresentar todas as qualidades necessárias para ser transformada em biodiesel (PURCINO; DRUMMOND,1986).
Segundo Forson, Oduro, Hammond (2004) e Severino et al. (2006) a espécie $J$. curcas é tolerante a longos períodos de estiagem e precipitações pluviométricas entre 600 e $1.500 \mathrm{~mm} \mathrm{ano}^{-1}$, podendo ser cultivada em região semiárida e em terras de pouca fertilidade "marginais" (terrenos acidentados; terras ao longo de canais de irrigação e de linhas férreas; em solos degradados por plantios intensivos, pastoreio ou mineração), desenvolvendo-se de acordo as condições climáticas dessas regiões.

Para Albuquerque, Lucena e Cunha (2008), a resistência a pragas e doenças, em J. curcas (Figura 2), é algo que precisa ser elucidado. Sabe-se que o Pachycoris torridus (Scopoli, 1772) (Hemiptera: Scutelleridae) é a principal praga, no entanto já foi constatada a ocorrência de outras, como: cigarrinha-verde (Empoasca sp (Hemiptera: Cicadellidae), ácaro branco (Polyphagotarsonemus latus (Banks, 1904) (Acari: Tarsonemidae), ácaro vermelho Tetranychus sp (Thysanoptera: Thripidae) (SATURNINO et al., 2005). 
Figura 2 - Plantação de J. Curcas localizada no Centro de Ciências Agrárias da Universidade Federal de Alagoas (CECA/UFAL), onde os experimentos, do presente trabalho, foram conduzidos.

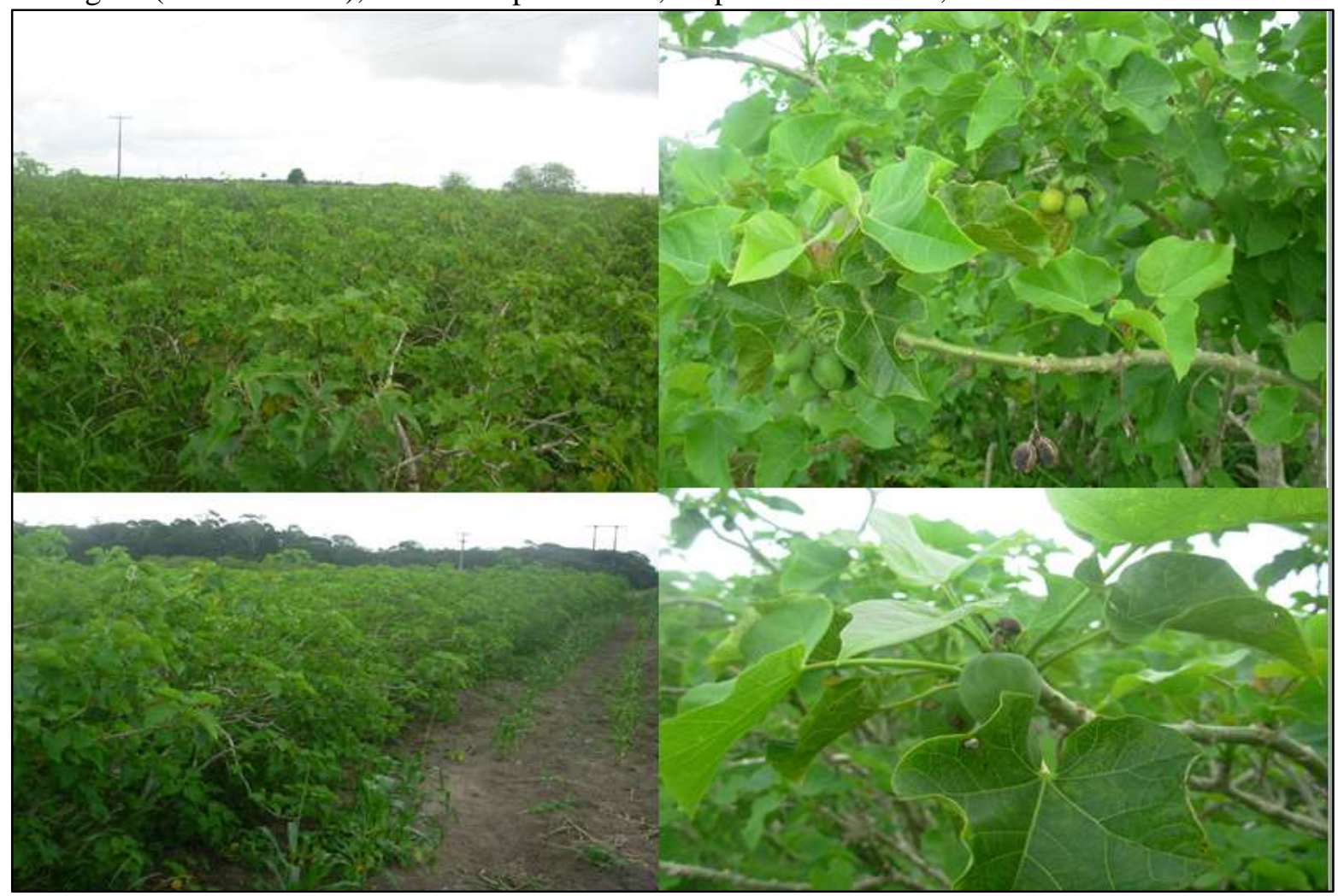

Fonte: Elaborada pela autora.

Jatropha curcas é uma espécie de grande valor econômico. Essa matériaprima é usada na obtenção do biodiesel, como também, na construção de cerca viva, em indústrias farmacêuticas e cosméticas, na fabricação de sabão e tinta, no controle de erosão (redução da erosão do vento ou da água), como torta (adubo orgânico muito valioso) (OPENSHAW, 2000; AUGUSTUS; JAYABALA; SEILERB, 2002).

O governo brasileiro, em 2004, lançou um programa para reduzir ainda mais a dependência dos combustíveis fósseis na perspectiva de alavancar o cultivo de outras plantas com potencial para biodiesel. (SUAREZ; MENEGUETTI; FERREIRA, 2006).

O biodiesel foi introduzido na matriz energética brasileira a partir de 13 de janeiro de 2005, quando foi criada a Lei $\mathrm{n}^{\underline{0}}$ 11.097, a qual ampliou a competência administrativa da Agência Nacional de Petróleo (ANP), que passou a denominar-se de Agência Nacional de Petróleo, Gás Natural e Biocombustíveis. A ANP é responsável por estabelecer as normas regulatórias, autorizar e fiscalizar as atividades relacionadas à produção, transporte, transferência, armazenagem, estocagem, importação, exportação, 
distribuição, comercialização e avaliação de conformidade e certificação de biocombustíveis. O Brasil está entre os maiores produtores e consumidores de biodiesel do mundo (ANP, 2015).

Em 2008, pinhão-manso atraiu milhões de dólares em investimentos por ser considerada a matéria-prima que iria revolucionar a produção de biocombustíveis. Porém, os agricultores se depararam com a baixa quantidade de sementes obtida na safra ao ponto de não permitir uma rentabilidade razoável, por isso o pinhão-manso caiu em descrédito. Seis anos depois essa cultura foi domesticada (pinhão manso híbrido), graças a avanços no campo da genética molecular e na tecnologia de sequenciamento de DNA, por uma empresa norte-americana (SGB), sediada em San Diego, a qual desenvolveu a "Jatropha 2.0", nome batizado pelos funcionários desse startup (BIODIESELBR, 2014).

O lançamento da "Jatropha 2.0" atraiu olhares dos gigantes do setor energético, empresas de aviação e transnacionais que buscavam alternativas para os combustíveis, caso hauvesse um aumento nos preços do petróleo, além de promover uma alternativa que se adequasse as leis que determinam o uso de combustíveis com baixo teor de carbono. A SGB objetivou produzir 260 milhões de litros de combustível por ano e já tem contratos assinados para plantar $100 \mathrm{mil}$ hectares no Brasil, Índia e outros países. Jim Rekoske, vice-presidente de energias renováveis e produtos químicos da Honeywell, ao visitar os plantios de pinhãomanso da empresa na América Central disse: "É um dos poucos biocombustíveis que, acredito, tem potencial para suprir uma grande parcela do combustível utilizado hoje na aviação" (BIODIESELBR, 2014).

A produção de líquido bioenergético a partir de óleos vegetais é um negócio em expansão, esse mecanismo de desenvolvimento limpo (baixa emissão de carbono) e renovável tem atraído olhares de empresários, políticos e pesquisadores, isto se deve a necessidade de minimizar o uso de poluentes (combustíveis fósseis) que emitem gases de efeito estufa. De acordo com a National Biodiesel Board (associação que representa a indústria de biodiesel nos Estados Unidos) a queima de biodiesel pode emitir em torno de $67 \%$ menos hidrocarbonetos; $48 \%$ menos monóxido de carbono e $47 \%$ menos material particulado (que penetra nos pulmões) (ANP, 2015).

\section{Publicações sobre Jatropha curcas}

A plataforma Lens é uma infraestrutura cibernética global aberta para tornar o sistema de inovação mais eficiente, justo, transparente e inclusivo. Ao realizar 
pesquisa nessa plataforma usando os descritores integrados, Jatropha curcas, obteve-se 619 resultados referentes a patentes. Tais patentes $(n=1.348)$ estão sob a jurisdição (Figura 3) do Instituto Europeu de Patentes, Organização Regional Africana de Propriedade Intelectual (ARIPO), Organização de Patentes da Eurásia, Organização Mundial de Propriedade Intelectual (WIPO) e de mais 26 países, dos quais 13 não foram inseridos na Figura 3 por apresentarem apenas uma patente, sendo eles: Costa Rica, Cuba, Egito, El Salvador, Espanha, Hong Kong,
Alemanha, Malásia, Marrocos, Peru, República Dominicana, Rússia e Sérvia, além da Organização de Patentes da Eurásia que também só apresentou uma patente. Marker Terry L, Kalnes Tom N e Mccall Michael $\mathrm{J}$ são os principais inventores (Figura 4). A primeira patente foi publicada em 1980, nessa década era publicada em média 0,8 patente por ano. A partir de 2004 houve um acréscimo considerável, como mostra a Figura 5 e a maior explosão foi em 2013 com 217 patentes registradas (LENS, 2015).

Figura 3 - Jurisdição de patentes relacionadas com Jatropha curcas.

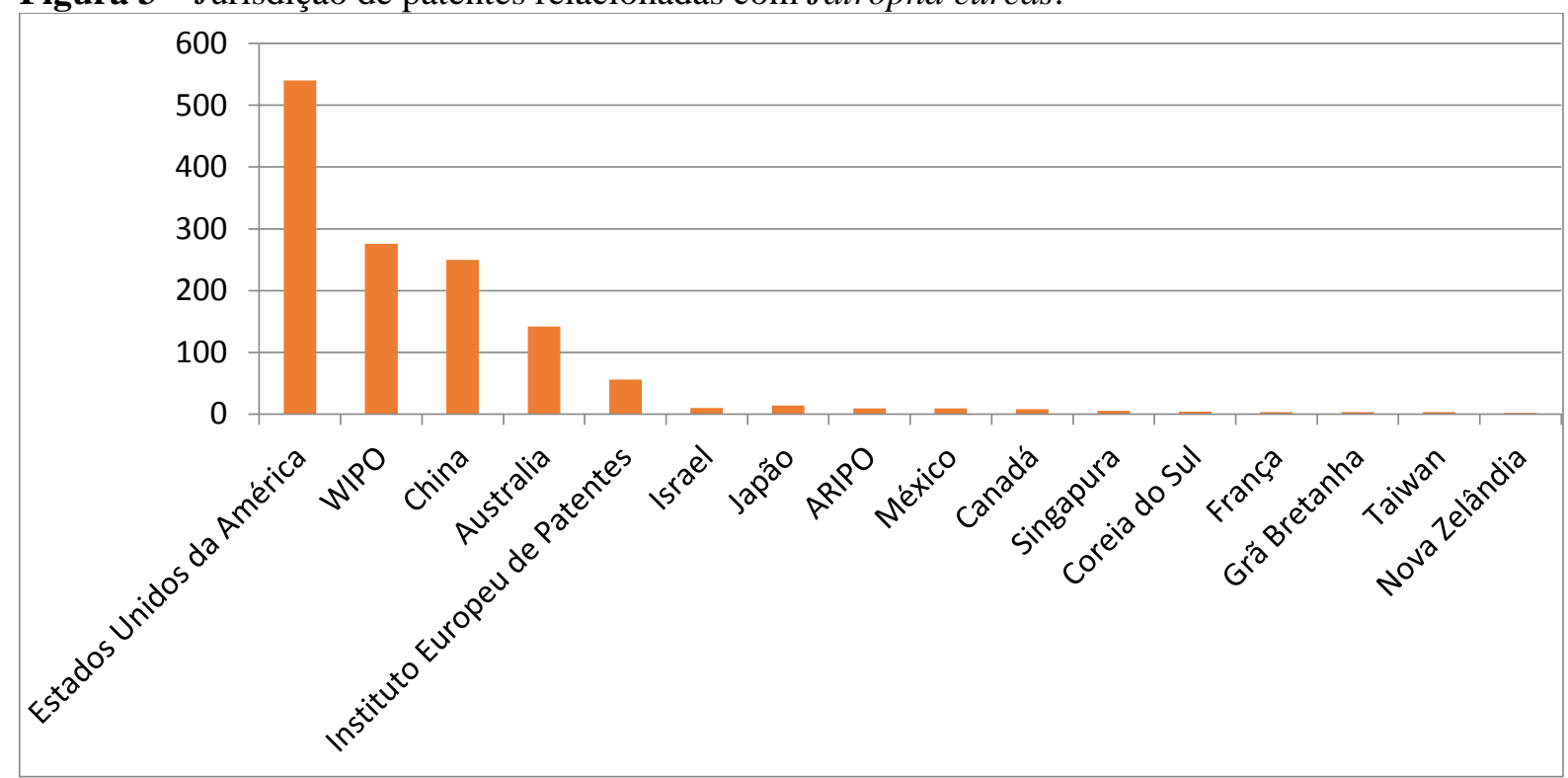

Fonte: Elaborada pela autora. Obtidos do banco de dados "lens. Org” (2015). 
Figura 4 - Principais inventores com registros de patentes relacionadas com Jatropha curcas.

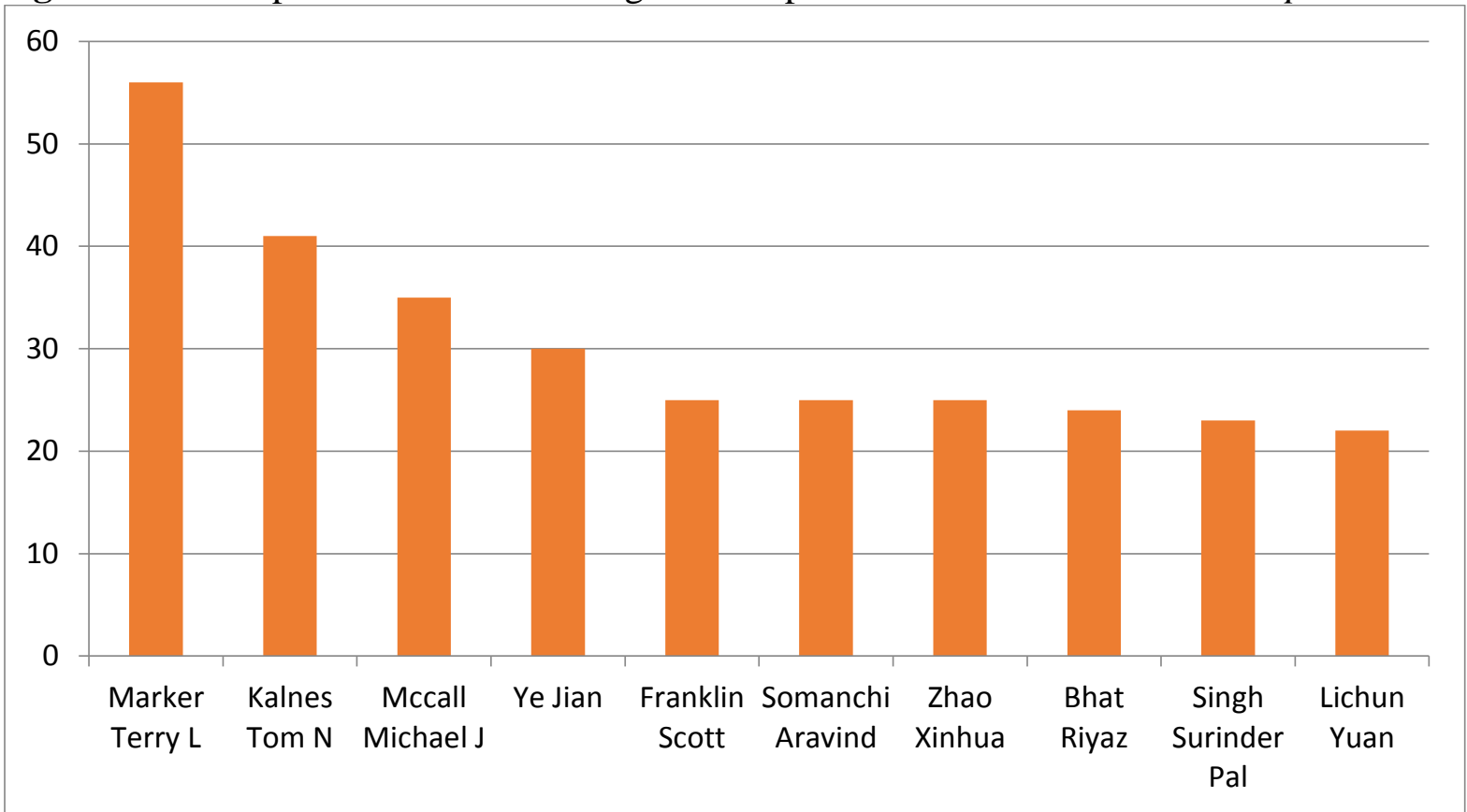

Fonte: Elaborada pela autora. Obtidos do banco de dados "lens. Org" (2015).

Figura 5 - Relação entre ano e número de patentes que envolve Jatropha curcas.

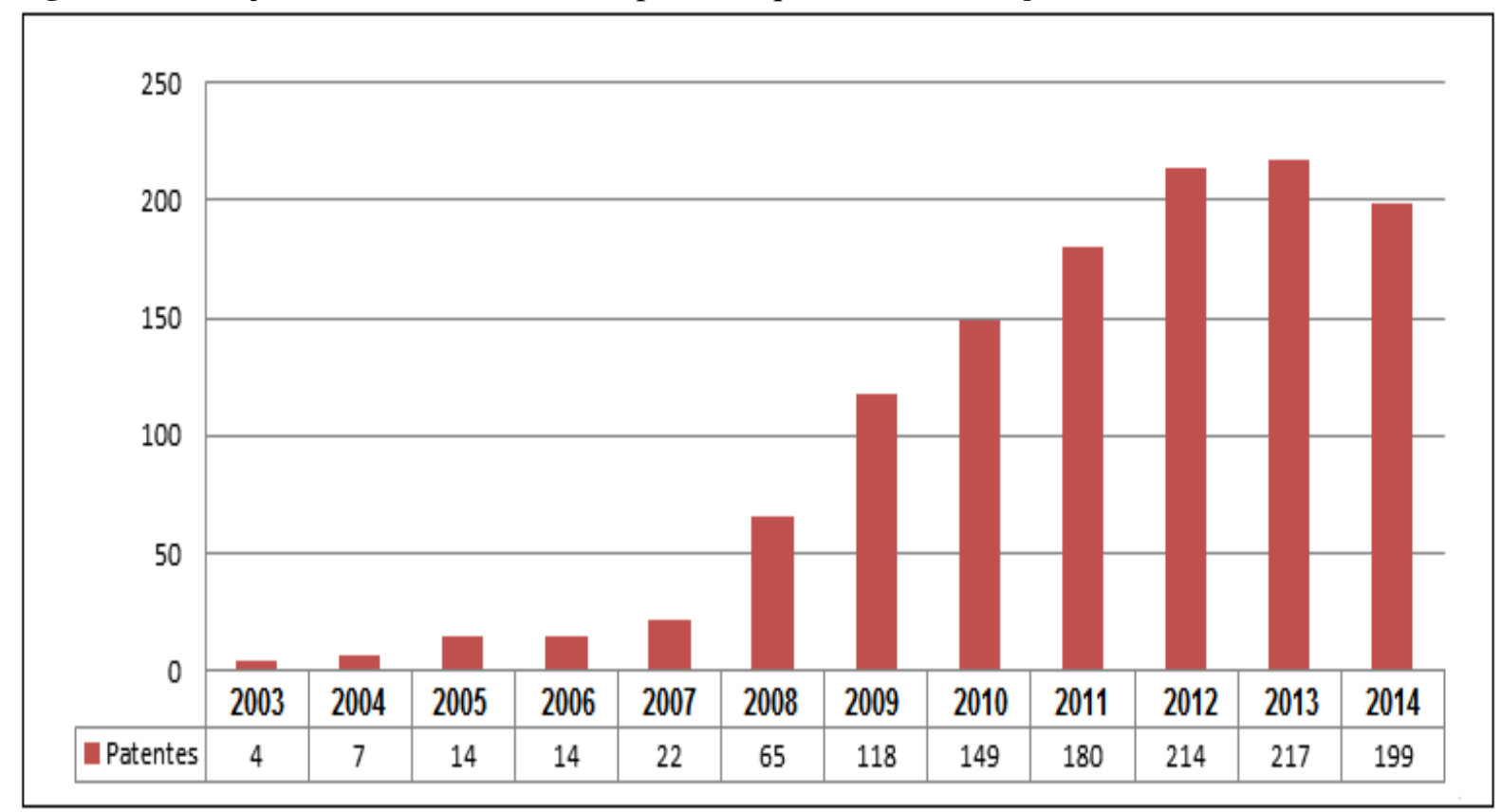

Fonte: Elaborada pela autora. Obtidos do banco de dados "lens. Org" (2015).

significativa, por meio do acesso ao

O Portal Periódicos da CAPES (uma das maiores bibliotecas virtuais do mundo, lançado em novembro de 2000), é uma das ferramentas, que contribui de maneira conteúdo científico de alto nível, no âmbito acadêmico nacional. Ao acessar esse portal usando os descritores integrados, Jatropha curcas foi possível obter 4.949 publicações 
relacionadas a esses termos, do tipo: artigos $(n=4.131)$, dissertações $(n=357)$, artigos de jornal $(n=317)$, recursos textuais $(n=109)$, atas de congressos $(n=44)$ e livros $(n=6)$. Publicados em diversos idiomas, dentre eles: ingês, português, espanhol, alemão, francês, holandês, chinês, indonésio, tailandês, russo, japonês e hindu. Disponíveis em 20 coleções, das quais seis possuem mais de 100 publicações, como: OneFile (GALE) $\quad(n=2.085), \quad$ SciVerse ScienceDirect (Elsevier) $\quad(\mathrm{n}=1.289)$, MEDLINE/PubMed (NLM) $\quad(\mathrm{n}=1.042)$, SpringerLink $(n=750)$, Directory of Open Access Journals (DOAJ) $(\mathrm{n}=497)$, SciELO Brazil (Scientific Electronic Library Online) ( $\mathrm{n}=127)$ e PMC (PubMed Central) $(n=123)$ (PORTAL PERIÓDICOS DA CAPES, 2015).

\section{Eficiência fotoquímica do processo fotossintético}

A revisão de literatura apresentada abaixo sobre esse tópico envolve parâmetros fisiológicos e morfológicos avaliados nos experimentos com mudas de Jatropha curcas (Linnaeus) (Euphorbiaceae), que se encontram no capítulo 3 desta tese.

O processo de conversão da energia luminosa em energia química, conhecido como fotossíntese $\left(\mathrm{CO}_{2}+\mathrm{H}_{2} \mathrm{O} \longrightarrow \mathrm{C}_{6} \mathrm{H}_{12} \mathrm{O}_{6}\right.$ $+\mathrm{O}_{2}$ ), principal fonte de carbono orgânico e de energia, permite que os vegetais incorporem biomassa. A medição da fotossíntese é uma maneira de avaliar o crescimento vegetal. Os pigmentos cloroplastídicos da folha absorvem a energia luminosa e reemitem parte na forma de fluorescência. Alterações no estado funcional das membranas dos tilacóides dos cloroplastos provocam mudanças nas características dos sinais dessa fluorescência (BAKER; ROSENQVST, 2004; SANTOS, 2008; CORRÊA; ALVES, 2010; WARDERLEY FILHO, 2011).

Para que as atividades fotossintéticas das plantas aconteçam satisfatoriamente é necessário que alguns fatores extríncicos estejam presentes e em quantidades recomendáveis, são eles: luminosidade, temperatura, pluviosidade, $\mathrm{CO}_{2}$ atmosférico, nitrogênio, umidade relativa, água e nutrientes minerais, entre outros. Dentre esses fatores, a luminosidade é um dos que tem maior relevância para o crescimento e desenvolvimento das plantas, pois é fonte primária de energia no processo de fotossíntese (PEARCY et al., 1991; GLYNN; FRASER; GILLIAN，2003; LARCHER, 2004; MARENCO; LOPES, 2005; SANTOS, 2008; CORRÊA; ALVES, 2010; WARDERLEY FILHO，2011).No entanto, as plantas, também respondem, drasticamente, ao déficit hídrico da seguinte maneira: com redução do tamanho, bem como de sua área foliar e produtividade 
(KRAMER, 1983; WARDERLEY FILHO, 2011).

O desenvolvimento dos vegetais está relacionado com todas as alterações que acontecem durante seu ciclo de vida, quer sejam qualitativas (diferenciação) e quantitativas (crescimento). $\mathrm{O}$ crescimento envolve aumento de tamanho e/ou peso, registrado ao longo do seu ciclo de vida, sendo de caráter quantitativo. Enquanto que, o desenvolvimento envolve todas as mudanças qualitativas (diferenciação) e quantitativas (crescimento) experimentadas pela planta. (CAIRO et al., 2008).

Os fatores ambientais são percebidos pelas células-guardas e esses sinais são integrados em respostas estomáticas bem definidas, de forma que a maior parte das plantas, em resposta negativa a esses fatores, fecham seus estômatos para diminuir a perda de água pela transpiração. Os estômatos, controlam a difusão de $\mathrm{CO}_{2}$ para o interior das folhas e a difusão de vapor de água para fora das folhas, isto provoca uma diminuição da condutância estomática (gs), menor assimilação de carbono e diminuição da taxa de fotossíntese (COSTA et al., 2001; TAIZ; ZEIGER, 2004; SANTOS, 2008; WARDERLEY FILHO, 2011).

A eficiência quântica efetiva do fotossistema II (ФPSII) correlaciona bem com a assimilação de $\mathrm{CO}_{2}$. Este método, não destrutivo, avalia qualitativamente a absorção de fótons (pelas clorofilas associadas ao fotossistema II), aproveitamento e transferência da energia luminosa na cadeia de transporte de elétrons representando a eficiência quântica desse transporte através do PSII. A eficiência quântica máxima (Fv/Fm), também usada como um indicador de danos fotoinibitórios, onde reflete a máxima eficiência com que a luz absorvida é convertida em energia química, expressa a eficiência na captura da energia de excitação pelos centros de reação abertos do PSII (KRAUSE; WEIS, 1991; MAXWELL; JOHNSON, 2000; BAKER; ROSENQVST, 2004; SANTOS, 2008).

A intensidade da fotoinibição pode ser avaliada pela redução das eficiências quântica máxima (Fv/Fm), à medida que fatores bióticos ou abióticos alteram a funcionalidade do fotossistema II. Quando os valores de $\mathrm{Fv} / \mathrm{Fm}$ são inferiores aos parâmetros de normalidade $(0,75-0,85)$, indicam um dano no aparato fotossintético (fotoinibição). Isto pode acontecer quando as plantas sofrem vários tipos de estresses, dentre eles: ataques de pragas, injúrias mecânicas, estresse hídrico e salino, aplicação de herbicidas. Assim, o uso de parâmetros da cinética de emissão de fluorescência permite detectar vários danos causados nas plantas (OGREN; OQUIST, 
1985; KRAUSE; WEIS, 1991; MAXWELL; JOHNSON, 2000; BAKER; ROSENQVST, 2004; KOCHEVA et al., 2004; CATUNDA et al., 2005; ZANANDREA et al., 2006; MARENCO et al., 2007; LIANG et al., 2007; TATAGIBA; PEZZOPANE, 2007; TROVÃO et al., 2007; SANTOS, 2008).

O SPAD (Soil Plant Analysis Development) é um medidor portátil de clorofila, que mede, instantaneamente, sem absorção e destruição das folhas, a transmissão de luz vermelha a $650 \mathrm{~nm}$ e de luz infravermelha a $940 \mathrm{~nm}$ através da folha. Seu Índice determina o teor relativo de clorofila total, uma vez que usa esses valores e os correlacionam com o teor de clorofila, por isso tem sido utilizado para estimar o conteúdo de clorofila em um grande número de espécies de plantas (KRAUSE; WEIS, 1991; ARGENTA et al., 2001; ZOTARELLI et al., 2003; SILVEIRA; BRAZ; DIDONET， 2003; BENETT et al., 2008; ROZANE et al., 2009; CORRÊA; ALVES, 2010).

Modelos matemáticos podem ser utilizados para expressar o crescimento e seus parâmetros (área foliar, taxa de crescimento, padrão de acúmulo e distribuição de massa seca), nas diversas partes do vegetal durante o seu ciclo de vida. Os dados gerados fornecem subsídios para compreender os diferentes processos fisiológicos envolvidos na morfogênese da planta (CALBO; SILVA; TORRES, 1989). $\mathrm{O}$ acúmulo de massa seca, em uma cultura vegetal, é dividido em três fases, devido às variações do ambiente $\mathrm{e}$ características fenotípicas. A duração de cada fase pode variar. $O$ padrão de crescimento abrange três fases, a saber: $1^{\mathrm{a}}$ ) Fase inicial (crescimento lento); $2^{\mathrm{a}}$ ) Fase de crescimento rápido: capaz de acumular cerca de 70 a $80 \%$ de toda massa seca; $3^{a}$ ) Fase em que o crescimento torna a ser lento: responsável pela acumulação de cerca de $10 \%$ de massa seca (MACHADO et al., 1982).

A massa seca acumulada pela planta durante $\mathrm{o}$ processo de fotossíntese corresponde $90 \%$, enquanto que os $10 \%$ restantes são oriundos da absorção de nutrientes minerais do solo (CAIRO et al., 2008). A matéria seca produzida pelas plantas, quando quantificada, permite avaliar a transformação de energia luminosa em energia química através do acúmulo de massa nas diferentes de partes da planta, como: folha, raiz e caule. Entretanto, o aspecto fisiológico de maior importância para a análise de crescimento é o acúmulo de materia seca resultante da fotossíntese líquida (fotoassimilados) (CAIRO et al., 2008; WARDERLEY FILHO, 2011).

Pachycoris torridus (Scopoli, 1772) (Hemiptera: Scutelleridae) 
Pachycoris torridus é um percevejo fitófago, quando adulto, alimenta-se de seiva do fruto, semente, caule e folhas. Apresenta um aparelho bucal sugador labial desde suas fases iniciais (ninfas), que se desenvolve (torna-se maior e mais resistente) ao atingir a fase adulta, a ponto de sugar qualquer parte da planta. Entretanto sua maior preferência, nesta fase, é o fruto verde ou maduro, quando presente. A herbivoria realizada nos frutos do Jatropha curcas (Linnaeus) (Euphorbiaceae), pelas ninfas e adultos desse heteroptero, promove: a formação do endosperma e queda da flor, chochamento das sementes em função da sucção de frutos imaturos, escurecimento, deformidade, consequentemente queda dos mesmos (aborto prematuro) e/ou diminuição de seu tamanho. A consequência dessa herbivoria afeta o teor de óleo, que pode reduzir até 50\% da produção (AMERICA， 2007; NAVA， DELMAR，2009; BROGLIOMICHELETTI et al., 2010; RODRIGUES et al., 2011; GABRIEL; FRANCO, 2012).

As culturas pertencentes às famílias Anacardiaceae (cajueiro, mangueira, aroeira vermelha), Euphorbiaceae (pinhão manso, mandioca, tungue e cansanção), Malpighiaceae (aceroleira), Myrtaceae (araçazeiro, eucalipto e goiabeira), Poaceae (arroz), Rubiaceae (café) Rutaceae (laranjeira) são potencialmente hospedeiras de percevejos do gênero Pachycoris (SILVA et al., 1968; GALLO et al., 2002; SANCHEZ-SOTO ， NAKANO， 2002; SÁNCHEZ-SOTO; MILANO; NAKANO, 2004; SANTOS et al., 2005; MICHELOTTO; SILVA; BUSOLI, 2006; NAVA, DELMAR, 2009), por isso, tais percevejos, são considerados polífagos (se alimenta de várias culturas).

Conhecido vulgarmente como "percevejo do pinhão bravo" (SILVA et al., 1968), P. torridus, possui ampla distribuição geográfica. $\mathrm{Na}$ América, (norte, centro e sul) foi registrado desde os Estados Unidos até a Argentina (FROESCHNER, 1988).

A ocorrência do percevejo $P$. torridus, em plantio de pinhão-manso, foi relatada por alguns pesquisadores em regiões diferentes no Brasil, tais como: Maranhão, Piauí, Minas Gerais, Alagoas e Rondônia (COSTA et al., 2001, AVELAR et al., 2007; SILVA, 2007; BROGLIOMICHELETTI et al., 2010).

Em Piracicaba, São Paulo, foi constatada a presença de $P$. torridus em frutos de acerola, durante o mês de abril do ano 2001 (SÁNCHEZ-SOTO; NAKANO, 2002). Em Minas Gerais, entre junho de 2004 e maio de 2005, a praga estava presente em toda plantação de $J$. curcas (SATURNINO et al., 2005) e no banco de germoplasma da mesma cultura da 
Universidade Federal de Lavras (UFLA), nos meses de dezembro a maio (AVELAR et al., 2007). Em Porto Velho, Rondônia, foi realizada amostragem para obtenção, da flutuação populacional e a maior porcentagem média de plantas infestadas pela praga aconteceu nos meses de março e abril de 2010, quando $50 \%$ das plantas amostradas tinham presente todas às fases do ciclo (COSTA et al., 2001).

Os frutos de araçá (Psidium araça Raddi) (Myrtaceae) e pinhão manso são adequados para o desenvolvimento e reprodução de $P$. torridus, no entanto, este percevejo adquire maior peso e vida útil quando alimentado com pinhão manso. Foi constatado, nas fêmeas alimentadas com pinhão manso, maior período de préoviposição e menores períodos de oviposição e pós-oviposição em relação às alimentadas com araçá (SILVA et al., 1968; FROESCHNER, 1988; SÁNCHEZ-SOTO; NAKANO， 2002; SÁNCHEZ-SOTO; MILANO; NAKANO, 2004; SANTOS et al., 2005; MICHELOTTO; SILVA; BUSOLI, 2006; SILVA, 2007; BROGLIOMICHELETTI et al., 2010; BORGES FILHO et al., 2013). Já experimentos realizados com frutos de tungue (Aleurites fordii (Hemsl.) (Euphorbiaceae)) mostraram que os mesmos não possibilitaram o desenvolvimento das ninfas dessa espécie (BORGES FILHO et al., 2013).

Pachycoris torridus é o único representante da família Scutelleridae de impacto agrícola no Brasil (MONTE, 1937; GALLO et al., 2002). A herbivoria por este percevejo está associada à diminuição da produtividade de plantas hospedeiras. $\mathrm{O}$ controle deve ser aplicado logo após a ocorrência dessa praga na cultura para se evitar a migração para outras (SANTOS et al., 2005; GABRIEL; FRANCO, 2012; BORGES FILHO et al., 2013). Entretanto, em 2010, não havia produto registrado pelo Ministério da Agricultura para o seu controle (BROGLIO-MICHELETTI et al., 2010). De acordo com Oliveira e Silva (2011) o parasitoide de ovos Telenomus pachycoris (Costa Lima, 1928) (Hymenoptera: Scelionidae) é o inimigo natural de $P$. torridus. Sendo assim, podemse adotar medidas para favorecer a presença dos ovos nas lavouras de pinhão manso.

\section{Morfologia}

A Figura 6 mostra a anatomia externa do percevejo da espécie Pachycoris torridus, o qual possui aparelho bucal sugador labial, representado por um rostro reto e alongado, de lábio constituído por quatro segmentos, transversalmente enrolados em forma de bainha, a qual se alojam os trophi (estiliformes), sendo duas 
externas (as mandíbulas), serradas no ápice e duas internas (as maxilas), reduzidas à peça intermaxilar. As maxilas apresentam duas escavações formando dois canais paralelos, um superior (anterior) por onde passa o alimento líquido aspirado pela faringe e outro inferior (posterior), por onde se escoa a saliva. Não há penetração nos tecidos perfurados pelos estiletes mandibulares e maxilares, nos atos de picar e sugar o lábio. O torax é quase que exclusivamente representado pelo pronoto. O abdômen é constituído de 9 segmentos no macho e 10 na fêmea ( $1^{\circ}$ segmento muito reduzido). É facil distinguir o macho da fêmea pela configuração dos segmentos terminais do abdômen (COSTA LIMA, 1940).

Figura 6 - Pachycoris torridus, fêmea lado esquerdo e macho lado direito. Face ventral. 1, buccula; 2, gula; 3 , propleura; 4, dropleura; 5, mesosterno; 6 , mesoepisterno; 7 , mesoepimeron; 8 , orifício (ostiolo) e canal da glândula odorífera; 9, metaepisterno; 10, luetaepimeron; 11, estigmas respiratórios dos urosternitos 2-6; 12, áreas estridulatórias; 13 e 14, segmentos da genitália; $15,7^{\circ}$ urosternito; $16,6^{\circ}$ urosternito; $17,2^{\circ}$ urosternito; $18,4^{\circ}$ segmento do lábio; $19,3^{\circ}$ segmento do lábio; $20,2^{\circ}$ segmento do lábio; 21, metasterno; 22, protorax; 23, $1^{\circ}$ segmento do lábio; 24, labrum; 25, tylus (clipeo), 26, $5^{\circ}$ urosternito; $27,4^{\circ}$ urosternito; $28,3^{\circ}$ urosternito (COSTA LIMA, 1940).

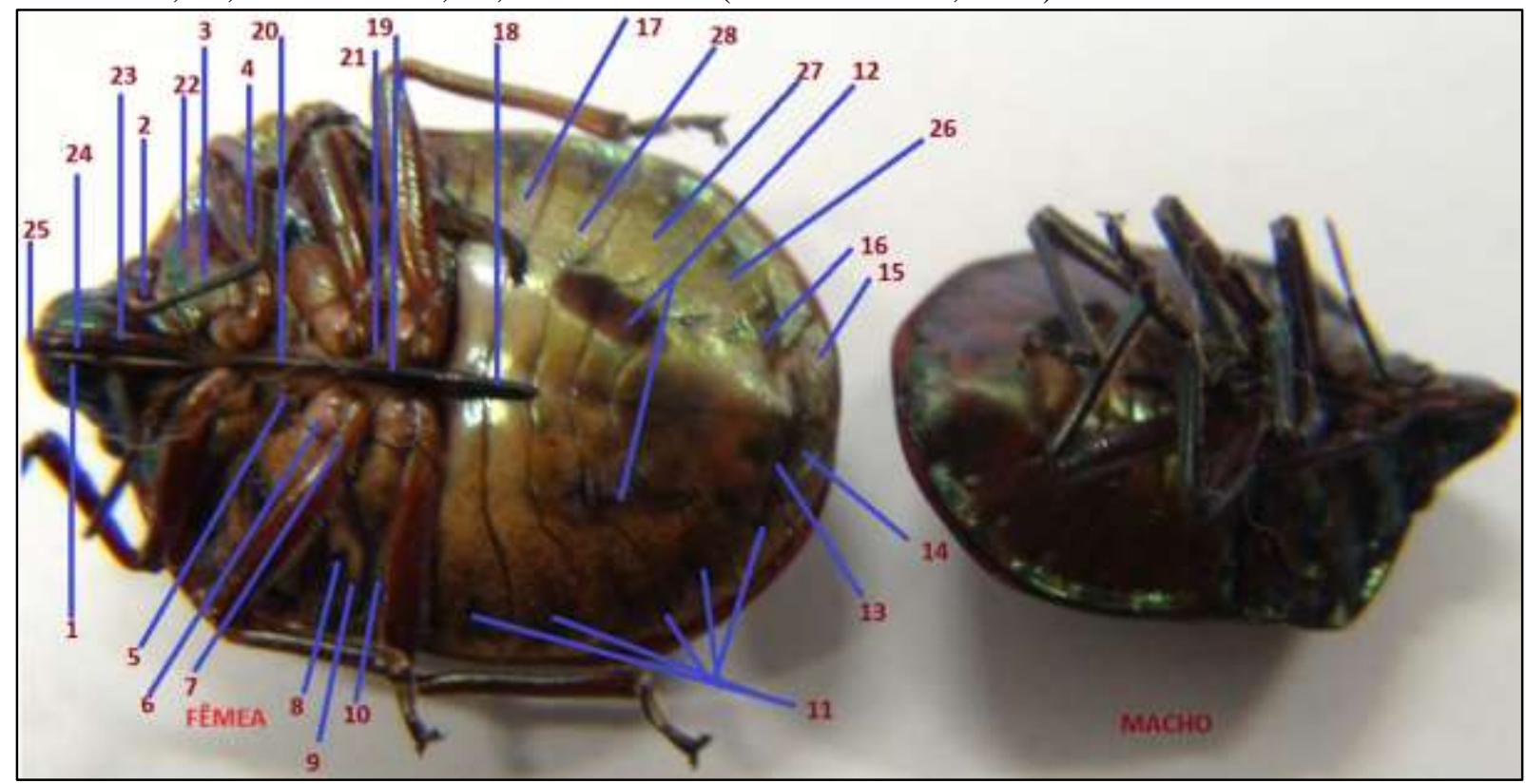

Fonte: Elaborada pela autora.

\section{Padrões cromáticos}

Em 1940, Costa Lima, justificou a importância de se registrar as variações nos padrões cromáticos para evitar erros, por pesquisadores, na catalogação de novas espécies em entomologia, ao atribuir nomes distintos a mesma espécie. Em cinco ocasiões, desde 1937, foram registrados novos padrões cromáticos de Pachycoris torridus, totalizando 27 variações (MONTE, 1937; SÁNCHEZ-SOTO; MILANO; NAKANO, 2004; SANTOS et 
al., 2005; PIKART et al., 2011 e SOUZA et al, 2012).

$\mathrm{Na}$ face dorsal, forma convexa, as diferenças fenotípicas são variadas e o padrão cromático básico de $P$. torridus (Figura 7) é descrito de acordo com o colorido do dorso, o qual se apresenta nas cores marrom, verde e preto. Nas estruturas anatômicas do pronoto e escutelo há presença de 22 máculas, com diferentes tonalidades de amarelo e vermelho, distribuídas da seguinte forma: pronoto com oito e escutelo com 14 (MONTE, 1937; SÁNCHEZ-SOTO; MILANO; NAKANO, 2004; SANTOS et al., 2005; PIKART et al., 2011 e SOUZA et al, 2012).

Figura 7 - Padrão cromático básico de $P$. torridus: quantidade e posição das máculas no pronoto e escutelo.

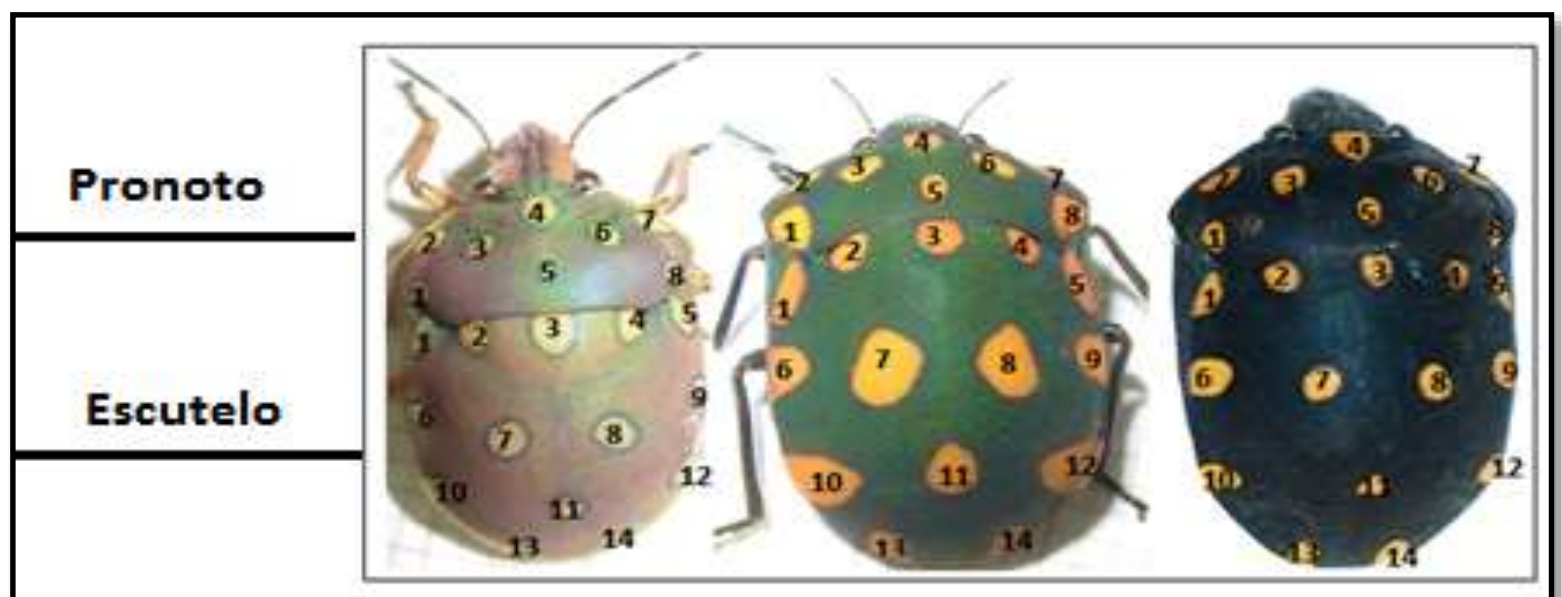

Fonte: Elaborada pela autora.

cobre, com reflexos de verde metálico

A porção ventral (Figura 8) e patas (MONTE, 1937).

possuem coloração verde metálico ou

Figura 8 - P. torridus. A - Macho, face ventral; B - Fêmea, pata inferior direita. 


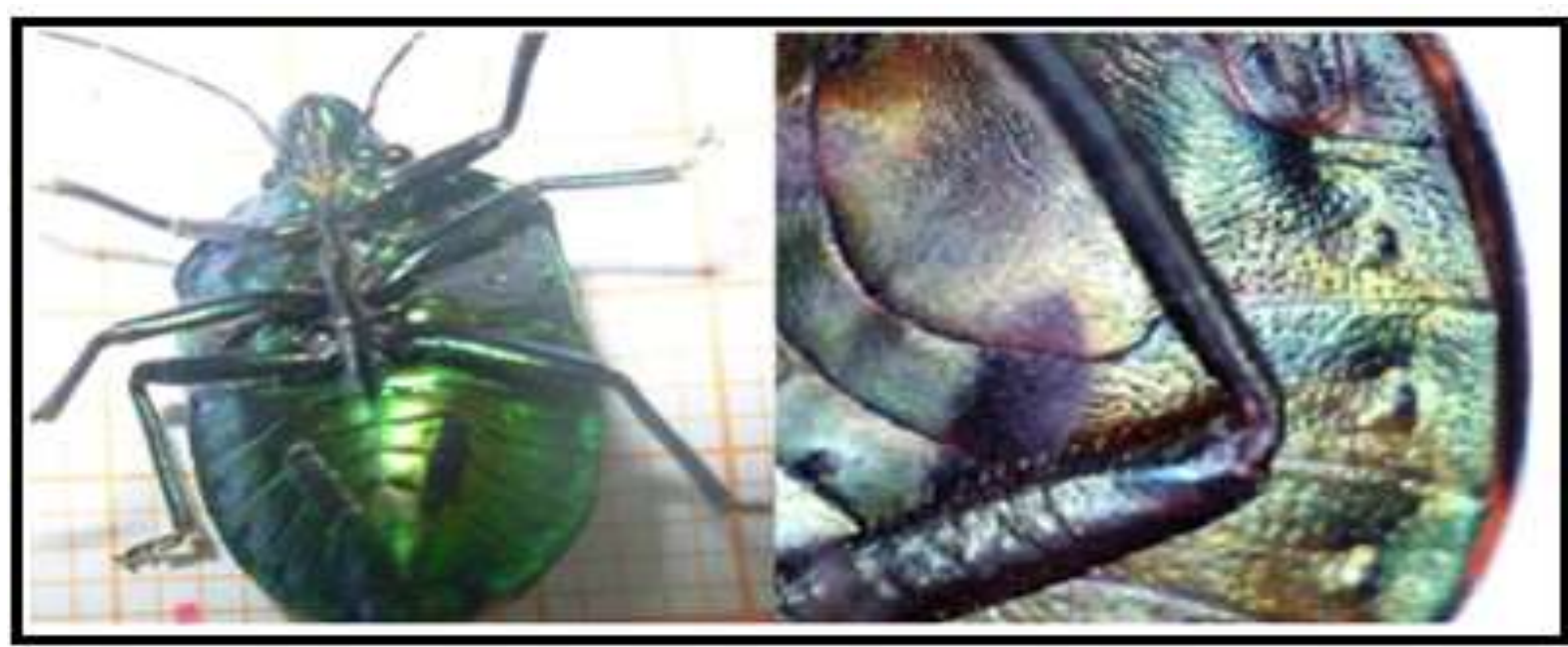

Fonte: Elaborada pela autora.

\section{Glândulas}

As glândulas salivares (bem desenvolvidas) são constituídas, de cada lado, pela glândula principal e por uma glândula acessória tubulosa, cujo canal excretor se reune ao da glândula principal num canal excretor único. O canal excretor comum é resultado da reunião dos dois canais excretores, da glândula direita e da esquerda, que se abre na chamada bomba salivar situada no hipofaringe. Os orifícios de entrada e de saida da bomba apresentam dispositivos valvulares que impedem o refluxo da saliva. Hidratos de carbono são hidrolizados pela saliva, esta é capaz de dissolver a celulose e de plasmolizar as células vegetais, facilitando a penetração dos estiletes do rostro (COSTA LIMA, 1940).

As glândulas odoríferas secretam substâncias de alarme, com odor característico da espécie. Nas ninfas tais glândulas, situam-se no abdome e são conhecidas como glândulas abdominais dorsais. Quando adultos tais glândulas são substituídas pela volumosa glândula metatorácica, a qual possui dois canais excretores (COSTA LIMA, 1940).

As glândulas anexas (machos) e coletéricas (fêmeas), presentes nos órgãos reprodutivos, secretam substâncias que servem para unir os ovos para o substrato sobre o qual são colocados (GALLO et al., 2002).

\section{Reprodução e ciclo biológico}

Os percevejos reproduzem-se por anfigonia e são ovíparos, seus ovos são colados uns ao lado dos outros, formando grupos. O número de ovos é mais ou menos constante. Tais percevejos fendem os tecidos das plantas, depositando os ovos no fundo das incisões (posturas endofíticas) sobre as folhas. A metamorfose é incompleta do tipo paurometabolia. Até o 
inseto atingir a fase adulta, observam-se cinco ecdises, onde são liberadas as exúvias (Figura 9), precedidas de cinco estádios de formas jovens (Figura 6) (COSTA LIMA, 1940).

Figura 9 - Exúvias liberadas no processo de troca de instar da espécie $P$. torridus: (A) $1^{\circ}$ instar; (B) $2^{\circ}$ instar; (C) $3^{\circ}$ instar; (D) $4^{\circ}$ instar; (E) $5^{\circ}$ instar e (F) Exúvias de todos os instares, em fileira na ordem crescente.

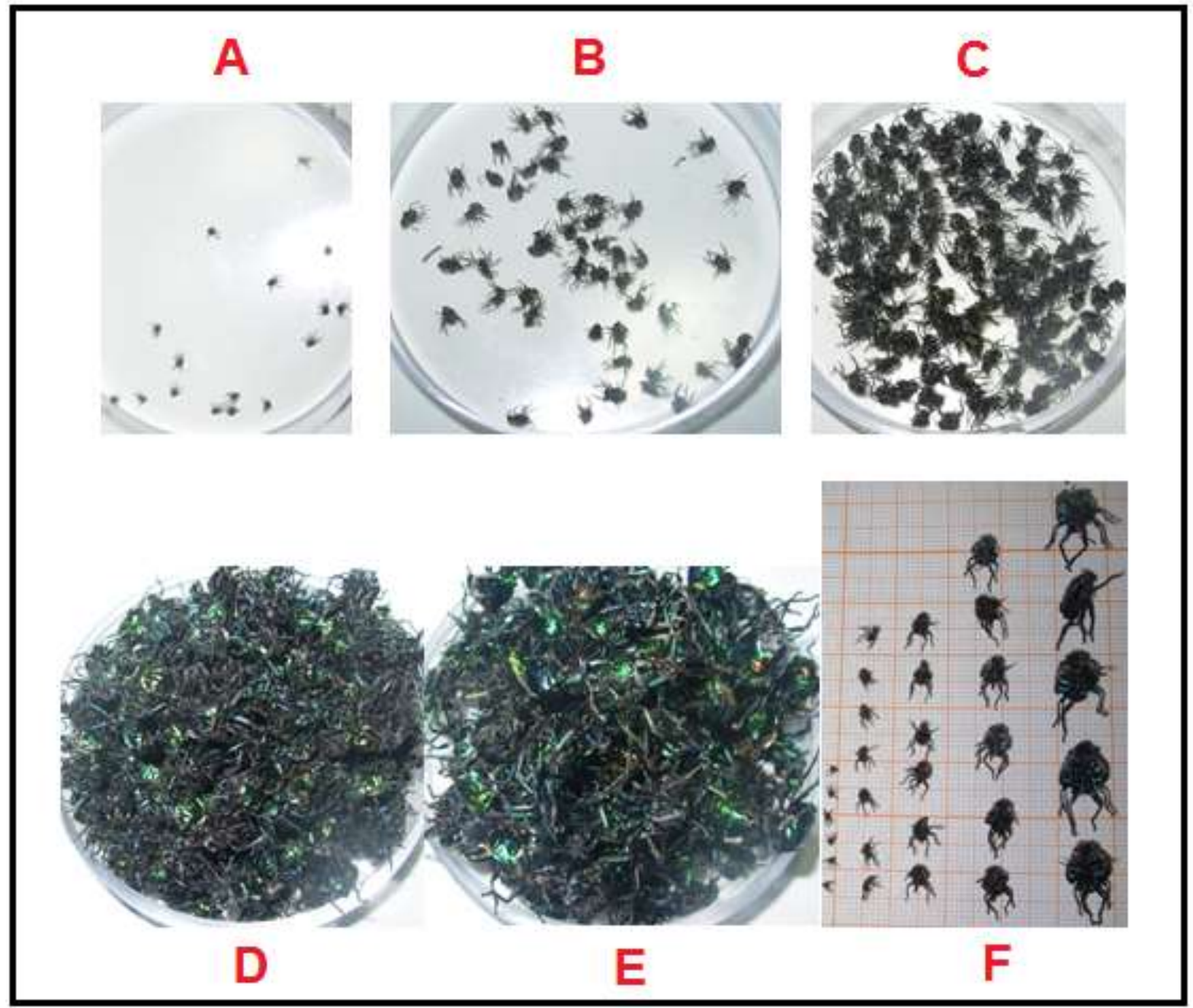

Fonte: Elaborada pela autora.

(GABRIEL et al., 1988; RODRIGUES I et

O número de ovos de $P$. torridus varia em média de 57,6 , a 87,21 por postura al., 2011). Fêmeas alimentadas com Psidium cattleianum (Myrtaceae) 
(araçazeiro) apresentam 59,15 ovos (viabilidade de $32,10 \%$ ), e com $J$. curcas (pinhão-manso) 42,3 ovos (viabilidade de 51,50\%) (BORGES FILHO et al., 2013). Fêmeas protegem os ovos ficando sobreposta aos mesmos até a eclosão das

\section{Desenvolvimento embrionário}

Período de pré-oviposição compreende o intervalo de tempo da cópula à primeira oviposição. Segundo Rodrigues I et al. (2011), são 15 dias em média, para os percevejos iniciarem as oviposições após a cópula.

O período de pós-oviposição conhecido como período de incubação após a oviposição. Para Rodrigues I et al. (2011) esse período tem duração de 12,7 dias na fase ovo. Borges Filho et al (2013) afirmaram que esse período é três vezes maior para os insetos alimentados com Psidium cattleianum (Sabine) (Myrtaceae) (68,9 dias) em relação aos que receberam dieta de Jatropha curcas (Linnaeus) (Euphorbiaceae) (20,7 dias).

O período embrionário é o tempo compreendido entre a cópula e a eclosão das ninfas de $2^{\circ}$ instar (SANTOS et al., 2005). Ao manipular os ovos as fêmeas a abandonam e não mais retornam a protegêlos (RODRIGUES I et al., 2011).

ninfas de $1^{\mathrm{o}}$ instar. De acordo com Rodrigues I et al. (2011), na espécie $P$. torridus, esse período dura em média 12,7 dias.

\section{Distribuição geográfica de percevejos (insetos-praga)}

Os percevejos estão assumindo um papel de destaque como insetos-praga na agricultura mundial. As espécies da família Pentatomidae, seguida da Coreidae estão entre as pragas que mais causam impacto nas lavouras. As culturas da soja, arroz e milho estão vivenciando o descontrole ecológico de percevejos, os quais representam as pragas-chave desde a floração até o amadurecimento dos grãos (SCHAEFER; PANIZZI, 2000; FERREIRA; BARRIGOSSI; VIEIRA, 2001; LAUMANN et al., 2003, KIM; LEE, 2008; ZARBIN; RODRIGUES; LIMA, 2009; RODRIGUES II, 2011).

O complexo de pragas da soja, nos Estados Unidos, é formado pelas espécies de percevejos: Acrosternum hilare (Say, 1832) (Hemiptera: Pentatomidae), Euschistus servus (Say, 1832) (Hemiptera: Pentatomidae) e Nezara viridula (Linnaeus, 
1758) (Hemiptera: Pentatomidae), essa última é cosmopolita, pois ataca diversos tipos de cultura (BORGES; ALDRICH, 1994). Na índia e Coréia, merecem destaque as pragas da soja Piezodorus rubrofasciatus (Fabricius, 1787) (Hemiptera: Pentatomidae) e Piezodorus hybneri (Gmelin, 1790) (Hemiptera: Pentatomidae) (SINGH; SINGH; THAKUR， 1989; PANIZZI, 1997; SON et al., 2000). Enquanto que, na África a praga Aspavia armigera (Fabricius, 1781) (Hemiptera: Pentatomidae) é a causadora de injúrias nessa soja (PANIZZI, 1997; RODRIGUES II, 2011).

No Brasil, o percevejo Euschistus heros (Fabricius, 1794) (Hemiptera: Pentatomidae) é a principal espécie do complexo da família Pentatomidae na região Centro-oeste, que causa injúrias à soja, especialmente na região do Distrito Federal (PANIZZI; SLANSKY, 1985; PIRES et al., 2006). Outros que compõem esse complexo são: Thyanta perditor (Fabricius, 1794) (Hemiptera: Pentatomidae), Edessa meditabunda (Fabricius, 1794) (Hemiptera: Pentatomidae), Piezodorus guildinii (Westwood, 1837) (Hemiptera: Pentatomidae), $N$. viridula, Dichelops furcatus (Fabricius, 1775) (Hemiptera: Pentatomidae), Dichelops melacanthus (Dallas, 1851) (Hemiptera: Pentatomidae),
Oebalus poecilus (Dallas, 1851) (Hemiptera: Pentatomidae), Oebalus ypsilongriseus (DeGeer, 1773) (Hemiptera: Pentatomidae), Tibraca limbativentris (Stal, 1860) (Hemiptera: Pentatomidae) (BORGES et al., 1999; ZARBIN et al., 2000; LAUMANN et al., 2003; PIRES et al., 2006). Ultimamente o E. heros e $P$. guildinii têm apresentado as mais altas densidades populacionais (PIRES et al., 2006; RODRIGUES II, 2011).

A cultura do arroz sofre ataques de percevejos em continente extremos como na Ásia e América (do Norte e do Sul). No primeiro a espécie em destaque é a Scotinophara lurida (Burmeister, 1834) (Hemiptera: Pentatomidae) (KIM; LEE, 2008), no segundo o percevejo Oebalus pugnax (Fabricius, 1775) (Hemiptera: Pentatomidae) se destaca como uma importante praga nos Estados Unidos (HILL, 1983); a espécie O. poecilus é uma praga potencial dessa cultura na América latina, juntamente com as espécies $O$. ypsilongriseus, Oebalus grisesens (Dallas, 1851) (Hemiptera: Pentatomidae), $D$. furcatus, D. melacanthus, Edessa meditabunda (Fabricius, 1794) (Hemiptera: Pentatomidae), E. heros, N. viridula, $P$. guildinii e T. limbativentris, causam injúrias nas plantações brasileiras (PANIZZI, 1997; FERREIRA; BARRIGOSSI; VIEIRA, 2001; LAUMANN et al., 2003; ZARBIN; 
RODRIGUES; LIMA, 2009; RODRIGUES II, 2011).

A cultura do milho, em diversas regiões, sofre injúrias causadas pela espécie Leptoglossus zonatus (Dallas, 1852) (Heteroptera: Coreidae) (HILL, 1983; SOUSA; AMARAL-FILHO, 1999). No Brasil, as culturas do milho, frutíferas e tomate sofrem ataques das espécies: Corecoris dentiventris (Berg, 1884) (Hemiptera: Coreidae), Corecoris fuscus (Thunberg, 1783) (Hemiptera: Coreidae), Diactor bilineatus (Fabricius, 1903) (Hemiptera: Coreidae), Holymenia clavigera (Herbst, 1784) (Hemiptera: Coreidae), Leptoglossus gonagra (Fabricius, 1775) (Hemiptera: Coreidae), L. zonatus, Leptoglossus stigma (Herb, 1784) (Hemiptera: Coreidae), Lybindus dichrous (Stal, 1860) (Hemiptera: Coreidae) e Phthia picta (Drury, 1770) (Hemiptera: Coreidae) (ZARBIN; RODRIGUES; LIMA， 2009; RODRIGUES II, 2011).

A cultura do cacau, na África, é atingida por ataques de percevejos das espécies Antiteuchus tripterus (Fabricius, 1787) (Hemiptera: Pentatomidae) e Bathycoelia thalassina (Herrich-Schaeffer, 1844) (Hemiptera: Pentatomidae) (GERALD， 1965; ENTWISTLE， 1972; OWUSU; MANU, 2008). Já a horticultura japonesa sofre ataques das pragas Plautia stali (Scott, 1874) (Hemiptera:
Pentatomidae) e Halyomorpha mista (Uhler, 1860) (Hemiptera: Pentatomidae) (KAWADA; KITAMURA， 1983). $\mathrm{Na}$ Rússia e Europa Oriental a espécie Eurygaster integriceps (Puton, 1881) (Hemiptera: Scutelleridae) causa injúrias à cultura do trigo (KIVAN, 2005; RODRIGUES II, 2011).

Na América, (norte, centro e sul), a cultura do gênero Jatropha tem sofrido ataques do percevejo Pachycoris torridus (Scopoli, 1772) (Hemiptera: Scutelleridae), espécie estudada no presente trabalho. No Brasil, essa praga foi encontrada realizando herbivoria em plantio de Jatropha curcas (Euphorbiaceae) em diferentes regiões (Maranhão, Piauí, Minas Gerais, Alagoas e Rondônia) (COSTA et al., 2001; AVELAR et al., 2007; SILVA, 2007; BROGLIOMICHELETTI et al., 2010).

Enfim, os percevejos fitófagos são pragas de uma multiplicidade de culturas e devem ser tratados com programas de manejo integrado (MCPHERSON; MCPHERSON, 2000).

\section{Corte e cópula de percevejos}

A competição entre machos e a escolha da fêmea são mecanismos da seleção sexual (THORNHILL; ALCOCK, 1983). Para alguns pesquisadores o sucesso da cópula depende dos recursos oferecidos como território, morfologia genital, peso e 
tamanho do macho ou o comportamento de corte (ANDERSSON, 1994; ANDERSSON; IWASA, 1996, TADLER; NEMESCHKAL; PASS, 1999; ŽUNIČ et al., 2008).

$\mathrm{O}$ peso e o tamanho dos insetos podem sofrer influência da alimentação, sendo assim, a mesma, além de afetar o desenvolvimento dos insetos também interfere na reprodução dos mesmos. $\mathrm{Na}$ tentativa de comprovar esse fato foi realizada uma avaliação do desenvolvimento e reprodução de Pachycoris torridus alimentados com frutos de araçá e pinhão manso. Os resultados constataram que o percevejo adquire maior peso e vida útil quando alimentados com pinhão manso. Observou-se, também, que fêmeas alimentadas com pinhão manso, apresentaram maior período de préoviposição e menores períodos de oviposição e pós-oviposição em relação às alimentadas com araçá (SILVA et al., 1968; FROESCHNER, 1988; SÁNCHEZ-SOTO; NAKANO, 2002; SÁNCHEZ-SOTO et al., 2004; SANTOS et al., 2005; MICHELOTTO; SILVA; BUSOLI, 2006; SILVA，2007; BROGLIO-MICHELETTI et al., 2010; BORGES FILHO et al., 2013).

Rodrigues et al. (2009), contestaram a literatura, ao verificaram na espécie de percevejo Podisus nigrispinus (Dallas, 1851) (Hemiptera: Pentatomidae) que machos e fêmeas não apresentaram preferência por parceiros no acasalamento; o tamanho do macho não influenciou na duração da cópula, escolha do parceiro e fertilidade das fêmeas. Os mesmos autores também observaram que fêmeas com cópulas interrompidas após 30, 60, 120 e 240 min apresentaram baixa viabilidade de ovos $(0 ; 3,1 ; 7,7$ e $34 \%$, respectivamente). Contudo, aquelas com tempo natural de cópula (338 a 671 min) alcançaram alta viabilidade, em torno de $74 \%$.

Machos que trazem maiores benefícios para as fêmeas podem ser os parceiros de suas escolhas, em múltiplas cópulas, (BERRIGAN; LOCKE, 1991; PARKER; SIMMONS, 1994). Os benefícios são ganho em material genético (pela manipulação da paternidade dos descendentes, impedimento de consanguinidade e diminuição de genótipos incompatíveis) e nutricional, de forma que machos de algumas espécies transferem, no material seminal, substâncias que serão utilizadas no processo de respiração celular e vitelogênese, na oviposição, na ativação e manutenção da viabilidade dos espermatozoides durante seu armazenamento na espermateca (OSANAI; CHEN, 1993; HERNDON; WOLFNER, 1995; REYNOLDS, 1996; ZEH; ZEH, 1996; KOSHIYAMA et al., 1996; TRAM; WOLFNER, 1999; EDVARDSSON; 
ARNQVIST, 2000; $\quad$ TREGENZA; WEDELL, 2002).

Em contrapartida, as fêmeas de várias espécies de insetos que realizam múltiplas cópulas, sofrem várias desvantagens, dentre as quais: não atingimento do número máximo de descendentes em um ou mais eventos reprodutivos devido à obtenção insuficiente de esperma; aumento da alocação de energia e tempo para a procura de parceiros; aumento do risco de predação e injúrias físicas provocadas pelos machos; efeito tóxico de substâncias transferidas junto ao material seminal; maior risco de contaminação por patógenos; redução de sua longevidade e fecundidade dos ovos, sendo estas duas últimas desvantagens observadas nas fêmeas de $P$. nigrispinus (THORNHILL; ALCOCK, 1983; ARNQVIST, 1989; RIDLEY, 1990; CHAPMAN et al., 1995; TORRES, ZANUNCIO; OLIVEIRA, 1997; CRUDGINGTON; SIVA-JOTHY, 2000; ROLFF; SIVA-JOTHY, 2002; SOUSASOUTO et al., 2006; RODRIGUES et al., 2008).

Alterações na largura e comprimento dos ovários do percevejo Spartocera dentiventris (Berg, 1884) (Hemiptera: Coreidae), permitem distinguir os estádios imaturo e reprodutivo desta espécie. No entanto, os órgãos de reprodução de machos não apresentam diferenças significativas nas diferentes idades (JAHNKE; REDAELLI; SANTOS, 2011).

É importante obter conhecimentos bioecológicos dos insetos para o controle de pragas, a fim de implantar táticas de manejo integrado. $\mathrm{O}$ estudo de aspectos relacionados à reprodução da espécie pode subsidiar essa busca, isto porque o aumento do risco da predação pode está relacionado com atividades reprodutivas, como procura de parceiros, corte e cópula (MAGNHAGEN, 1991), sendo as fêmeas mais suscetíveis à ação de predadores no período da oviposição (JAHNKE; REDAELLI; SANTOS, 2011).

\section{Programa de Manejo Integrado de Pragas (MIP)}

O Programa de Manejo Integrado de Pragas (MIP) é um modelo ideal de abordagem sistemática, o qual consiste na proteção a uma determinada cultura agrícola, a partir da observação, acúmulo de informações sobre as espécies e os respectivos índices de infestação, bem como racionalização das medidas a serem adotadas. Só assim é possível uma medida mais criteriosa das táticas de controle (BENVENGA; FERNANDES;

GRAVENA, 2007), a fim de reduzir a aquisição de insumos e minimizar as 
consequências sociais, econômicas e ambientais do processo de controle da praga alvo.

Várias estratégias de defesa do cultivo contra o inseto-praga podem ser aplicadas isoladamente ou simultaneamente, como: variedades resistentes, plantas geneticamente modificadas, uso de agroquímicos específicos, monitoramento com feromônio, uso de predadores ou parasitoides, utilização de microorganismos (entomopatógenos) (ZARBIN; RODRIGUES; LIMA, 2009), eliminação de condições propícias e reguladores de crescimento de insetos (SCHOWALTER, 2006).

O controle de pragas pelo MIP se faz por métodos biológicos, químicos e agrotécnicos, na tentativa de equilibrar custos e proteger o meio ambiente, beneficiando os produtores e a sociedade (BERGMANN; GONZÁLEZ; ZARBIN, 2009). Seus recursos são biotecnológicos, ecologicamente corretos e eficazes (MCNEIL, 1991).

\section{Semioquímicos}

O prefixo (semio) da palavra semioquímico é de origem grega (semeîon) e significa sinal. Os compostos utilizados na intermediação de relações entre os seres vivos são os sinais químicos conhecidos como semioquímicos. É por meio da detecção e emissão dessas substâncias que os insetos desempenham funções vitais, como: localização de parceiros para o acasalamento, alimento ou presa; escolha de locais para oviposição; seleção de plantas hospedeiras; defesa contra predadores e organização de suas comunidades (insetos sociais) (TEGONI et al., 2004; ZARBIN; RODRIGUES; LIMA, 2009).

A comunicação química, dos insetos, se faz por um grande número de semioquímicos com estruturas químicas variadas (PARK et al., 2002). Cada espécie possui o seu próprio código de comunicação baseado nas diferenças estruturais dos compostos, que permite criar uma linguagem entendida apenas por insetos da mesma espécie (BJOSTAD, 1998). Os feromônios fazem parte desse universo bastante amplo da comunicação intraespecífica (PARK et al., 2002) e os aleloquímicos da comunicação interespecífica, os quais intermedeiam os comportamentos de indivíduos de espécies diferentes. Os aleloquímicos são classificados em: cairomônios (beneficiam o indivíduo receptor), alomônios (beneficiam o emissor) e sinomônios (os dois são beneficiados) (ZARBIN; RODRIGUES; LIMA, 2009).

Os semioquímicos (feromônios, cairomônios, alomônios e sinomônios) 
podem auxiliar nos programas de Manejo Integrado de Pragas (MIP) por meio de armadilhas no campo atuando no confundimento, atratividade, bem como repelência dos insetos-praga da cultura que está sofrendo herbivoria, de forma a impedir que os insetos encontrem seu coespecífico para acasalamento e assim aumentem a proliferação da espécie (LIMA; DELLA LUCIA, 2001). Sabe-se que, os maiores avanços estão relacionados ao uso de feromônios sexuais, mesmo com inúmeras possibilidades de uso dos semioquímicos em estratégias de controle da herbivoria realizada por insetos fitófagos (ZARBIN; RODRIGUES; LIMA, 2009).

\section{Feromônios}

Feromônios são compostos voláteis secretados pelos animais, que geram um alto potencial de especificidade às mensagens (SILVERSTEIN; YOUNG, 1976; HÖLLDOBLER; CARLIN, 1987) e funciona como gatilhos fisiológicos de reações comportamentais específicas (PAIVA; PEDROSA-MACEBO, 1985), sendo classificado de acordo com o comportamento que exerce num indivíduo receptor (FERREIRA, 2012).

$\mathrm{O}$ primeiro a teorizar sobre a existência de compostos químicos intermediando o acasalamento de insetos foi o entomologista francês Jean-Henri
Fabre, em 1870, por meio de experimentos realizados com a mariposa da espécie Saturnia pyri (Denis; Schiffermüller, 1775) (Lepidoptera: Saturnidae) (AUSLANE, 2008; ZARBIN; RODRIGUES; LIMA, 2009; RODRIGUES, 2011).

Em 1959 o químico alemão Adolf Friedrich Johann Butenandt, premiado com o Nobel de Química de 1939, publicou juntamente com seus colaboradores o primeiro artigo que trata da identificação da estrutura química do feromônio sexual do bicho da seda, a mariposa Bombyx mori (Linnaeus, 1758) (Lepidoptera: Bombycidae), o qual ficou conhecido como bombicol, o álcool (E,Z)-10,12Hexadecadien-1-ol). Sua pesquisa foi resultado de 20 anos de trabalho. Posteriormente, em 1966, dois outros atrativos sexuais de mariposas foram identificados: Trichoplusia ni (Hübner, 1802) (Lepidoptera: Noctuidae) e Pectinophora gossypiella (Saunders, 1843) (Lepidoptera: Gelechiidae).

A necessidade de desenvolver técnicas atóxicas por meio do controle comportamental de pragas vem despertando o interesse da comunidade científica de ecologia química ao longo dos anos. Pesquisadores como Carson (1964), Shorey, Gaston e Saario (1967) atuaram no comportamento de insetos e demostrarem a 
confusão causada na comunicação química sexual de insetos da mesma espécie.

A mensagem mediada por compostos feromonais pode atingir longas distâncias, ou simplesmente atuar nas proximidades. Os feromônios sexuais são considerados de longa-distância, esses permitem atrair indivíduos do sexo oposto para acasalamento. Enquanto que, os feromônios de alarme são de curtadistância, sendo altamente voláteis, os quais permitem uma rápida dispersão dos sinais químicos para repelência. Os feromônios de agregação atuam em ambos os sexos possibilitando a agregação de indivíduos para um local específico para alimentação e/ou de acasalamento. Os insetos sociais organizam suas atividades nas colônias por meio de diversos feromônios, dentre eles os de marcação e de trilha (BARTELT, 1999; ZARBIN; RODRIGUES; LIMA, 2009).

Feromônios representam um dos principais componentes do manejo de pragas de base ecológica (SUCKLING, 2000). Dentre os tipos apresentados no parágrafo anterior, os que mais se destacam são os feromônios sexuais (MCNEIL, 1991), pela eficiência no controle do insetopraga. Seu uso está de acordo com o conceito preconizado pelo Manejo Integrado de Praga (MIP) (TREMATERRA, 2002) e se faz por meio do monitoramento, atratividade e interrupção do acasalamento (MCNEIL, 1991; $\quad$ SUCKLING, 2000; TREMATERRA, 2002). Ao comparar os feromônios com os agroquímicos, percebem-se inúmeras vantagens, dentre elas: são específicos, não tóxicos, usados em pequenas quantidades e biodegradáveis (LAUMANN et al., 2003).

O Manejo Integrado de Pragas por captura em massa através de armadilhas iscadas com feromônio de percevejos apresentam resultados satisfatórios, em nível experimental. Mas na prática, o controle comportamental no campo tem obtido resultados inferiores ao esperado. Acredita-se que os fatores relacionados com esse fato sejam: curta viabilidade dos feromônios sinéticos, armadilhas impróprias para captura de percevejos e período longo de acasalamento para essa subordem dos insetos (MILLAR et al., 2002). Talvez por isso ainda não exista uma estratégia comercial e de grande escala para controle de percevejos envolvendo feromônios (BORGES et al., 2007).

\section{Feromônios de alarme}

Feromônios de alarme são compostos químicos de defesa, altamente voláteis e de baixo peso molecular, os quais permitem uma rápida dispersão dos sinais químicos para alertar os indivíduos da mesma espécie (BILLEN, 2008). 
Funções secundárias, dos compostos de defesa, foram observadas ao pesquisar o homossexualismo em percevejos machos. Percebeu-se que percevejos masculinos usavam o feromônio de alarme para evitar a montagem, assédio homossexual e interromper o acasalamento completo entre macho-fêmea. Com a redução do período de acasalamento houve a diminuição da transferência de espermatozoides $\quad$ (RYNE, 2009); consequentemente reduziu a proliferação da espécie, quando usado no campo.

Os feromônios de alarme do percevejo Leptocorisa oratorius (Fabricius, 1794) (Hemiptera: Alydidae) foram identificados por Gunawardena e Bandumathie (1993). Ambas as secreções do gênero masculino e feminino consistiram em dois componentes principais: (E)-2-Octenal e Acetato de octila, com $76 \%$ e $16 \%$, respectivamente. Os restantes $8 \%$ eram compostos vestigiais, alguns dos quais foram identificados como o Acetato de hexila, 3-Octenal, 1-Octanol, e Acetato de (Z)-3-octenila. A resposta de alarme foi comprovada nos bioensaios com os extratos, em que fêmeas e machos agregados de Leptocorisa oratorius (Fabricius, 1794) (Hemiptera: Alydidae) se dispersaram ao perceberem a presença da secreção defensiva.
Paves et al. (1994) investigaram as secreções exócrinas dos cinco estádios ninfais do percevejo verde, Nezara viridula (Linnaeus, 1758)

(Heteroptera: Pentatomidae). As ninfas produziram uma mistura de cinco alcanos saturados lineares acíclicos com 12, 13, 14, 15 e 16 carbonos. As glândulas de ninfas de $1^{\circ}$ instar produziram os mesmos alcanos, vestígios de (E)-2-Decenal, e um composto específico: (E)-4-(oxo)-2-Decenal. Nos outros estádios $\left(2^{\circ}-5^{\circ}\right)$ não foi encontrado o (E)-4-(oxo)-2-Decenal, mas estava presente o composto (E)-4-(oxo)-2Hexenal. Por meio da olfatometria foi investigada a função biológica de (E)-4(oxo)-2-Decenal, a qual mostrou que este composto, em doses fisiológicas, no $2^{\circ}$ instar, atua como atrativo. Além disso, este semioquímico foi repulsivo para a formiga de fogo, Solenopsis geminata (Fabriciu, 1804) (Hymenoptera: Formicidae), um predador potencial de N. viridula.

De acordo com Leal, Panizzi e Niva (1994) os compostos de defesa não são específicos para os estádios de vida do Leptoglossus zonatus (Dallas, 1852) (Heteroptera: Coreidae), ou seja, adultos e ninfas possuem diferentes sistemas de feromônios de alarme. Os componentes de alarme em hemípteros não são espécieespecíficos, esta hipótese foi apoiada no experimento realizado com o feromônio de 
alarme, Ácido butanoico, oriundo da família Alydidae, que produziu repelência em adultos e ninfas de L. zonatus. No mesmo estudo foram identificados os compostos de defesa do L. zonatus (adultos): Acetato de Hexila, Hexanol, Hexanal e Ácido hexanóico. Em relação aos componentes individuais testados no campo o composto (E)-2-Hexenal, presente na secreção, somente, das ninfas, provocou dispersão em $70 \%$ dos adultos. Além disso, as ninfas de $1^{\circ}$ instar responderam aos quatro compostos, da mistura feromonal de adultos, citados acima.

Blatt et al. (1998) estudaram os feromônios de alarme de ninfas e adultos do percevejo Leptoglossus occidentalis (Heidemann, 1910) (Hemiptera, Coreidae), os quais identificaram: (E)-2-Hexenal, nas ninfas; Hexanal, Hexanol, Acetato de hexila, Acetato de Heptila e Acetato de Octila nas fêmeas e machos adultos. Os resultados obtidos dos bioensaios comportamentais, com esses compostos de alarme identificados por tais pesquisadores, indicam que os percevejos adultos são mais sensíveis ao seu próprio feromônio do que o feromônio produzido por ninfas da mesma espécie.

A espécie Cosmopepla bimaculata (Thomas, 1865) (Hemiptera: Pentatomidae) foi estudada por Krall et al. (1999), os quais concluiram que machos e fêmeas desse percevejo secretam uma mistura, de feromônios de alarme, semelhante. Possui em torno de 12 compostos voláteis: $(E)$-2Hexenal, Acetato de hexinila, Undecano, Dodecano, (E)-2-Decenal, 1-Trideceno, Tridecano, Tetradecano, Acetato de (E)-2decenila, Pentadecano. Cerca de 92\% da secreção consistia de apenas três componentes: Tridecano (68\%), (E)-2Decenal (12\%) e Acetato de $(E)$-2-decenila (12\%).

Zarbin et al. (2000) identificaram, a mistura feromonal (feromônios de alarme) nos extratos de glândulas metatorácicas, oriundos do percevejo adulto Piezodorus guildinii (Westwood, 1837). (Hemiptera: Pentatomidae), composta de sete substâncias, a saber: (E)-2-Hexenal, $(E)$-4(oxo)-2-Hexenal, (E)-2-Octenal, Undecano, Dodecano, 1-Trideceno e Tridecano, os dois primeiros compostos foram detectados como constituintes majoritários.

Os componentes voláteis, de Pachycoris stallii (Uhler, 1863) (Hemiptera: Scutelleridae), percevejo da mesma família da praga pesquisada neste trabalho, obtidos das secreções das glândulas abdominais dorsais (em ninfas do $1^{\circ}$ ao $4^{\circ}$ instar) e metatorácicas (em adultos) foram identificados por Williams, Evans e Bowers (2001).

Os mesmos pesquisadores encontraram, em ninfas de $P$. stallii, os 
seguintes compostos: (E)-2-Hexenal, $(E)-4$ (oxo)-2-Hexenal, Tridecano, Tetradecanal e Dodecano; este último estava presente, apenas, em ninfas de $2^{\circ}$ e $4^{\circ}$ instares. Nas fêmeas sem postura: $(E)$-2-Hexenal, $(E)$-4(oxo)-2-Hexenal, Dodecane, 1-Trideceno, Tridecano e traços de Acetato de (E)-2hexenila, Tetradecano, Pentadecano e nos machos: (E)-2-Hexenal, (E)-4-(oxo)-2Hexenal, Acetato de (E)-2-hexenila, Dodecane, 1-Trideceno, Tridecano e Pentadecano. Os compostos majoritários das ninfas foram (E)-4-(oxo)-2-Hexenal, Tridecano ( $1^{\circ}$ e $2^{\circ}$ instar $)$ e Tetradecanal ( $3^{\circ}$ e $4^{\circ}$ instar), enquanto que nos adultos foi o Tridecano, seguido do (E)-2-Hexenal (WILLIAMS, EVANS e BOWERS, 2001).

Marques et al. (2007) analisaram a glândula metatorácica do percevejo Dichelops melacanthus (Dallas, 1851) (Hemiptera: Pentatomidae) e identificaram (E)-2-Hexenal, Decano, Acetato de (E)-2hexenila, Undecano, (E)-4-(oxo)-2-Octenal, Dodecano, Acetato de (E)-2-octenila, 1Trideceno, Tetradecano e Pentadecano, sendo o Tridecano o componente majoritário, seguido de quantidades menores e aproximadamente iguais de $(E)$ 4-(oxo)-2-Hexenal e (E)-2-Octenal.

Pareja et al. (2007) estudaram as diferenças das secreções defensivas de ninfas, adultos fêmeas e machos de cinco espécies de heteropteros: Chinavia impicticornis (Stal, 1872) (Hemiptera: Pentatomidae) (Fêmeas: 4-Hidroxi-4-metil2-pentanono; Machos: Tridecano; Ninfas: (E)-4-(oxo)-2-Hexenal, Pentadecano); Chinavia ubica (Rolston, 1983) (Hemiptera: Pentatomidae) (Fêmeas: Acetato de (E)-2-decenila, Pentadecano, (Z)-2-Decenal; Machos: (E)-2-Hexenal, (E)-2-Octenal; Ninfas: composto desconhecido); D. melacanthus (Fêmeas: (E)-2-Octenal, Tetradecano; Machos: Tridecano, Pentadecano; Ninfas: Undecano, Dodecano, Tetradecanal); (Fabricius, 1794) (Hemiptera: Pentatomidae) (Fêmeas: Decano; Machos: (E)-2-Octenal, 1-Trideceno; Ninfas: Tetradecanal); Piezodorus guildinii (Westwood, 1837) (Hemiptera: Pentatomidae) (Fêmeas: Undecano, Tetradecano; Machos: (E)-4-(oxo)-2Hexenal, Tridecano, Pentadecano; Ninfas: Tetradecanal).

Para Pareja et al. (2007) o Tetradecanal é o composto predominantemente de ninfas em $D$. melacanthus, E. heros e P. guildinii. Nas ninfas das espécies $C$. impicticornis e $C$. ubica o (E)-4-(oxo)-2-Hexenal e outro composto desconhecido eram os majoritários. A três espécies diferiam entre si, ou seja, o (E)-2-Octenal foi detectado no D. melacanthus, o (E)-2-Hexenal no $P$. guildinii e (E,E)-2-4-Decadienal e 
Tetradecanal no E. heros. A análise conjunta das espécies revelou que o Tetradecanal e $(E)$-4-(oxo)-2-Decenal são fortemente associados às ninfas. Para esses pesquisadores, existem diferenças previsíveis entre os estádios do ciclo biológico e as espécies. O estudo dessas diferenças pode vir a ser importante no esclarecimento das interações que envolvem os inimigos naturais dos percevejos e a emissão de compostos de defesa por estes últimos.

Durak e Kalender (2009) ao estudarem o percevejo Graphosoma lineatum (Linnaeus, 1758) (Heteroptera, Pentatomidae) detectaram nos extratos da glândula metatorácica de fêmeas e machos quatorze feromônios de alarme pertencentes aos seguintes grupos químicos: alcanos, alcenos, aldeídos, acetatos, esteroides e ácidos. Os compostos químicos encontrados nas fêmeas foram: $(E)$-2Hexenal, Ciclohexano, Acetato de (E)-2hexenila, Undecano, Dodecano, (E)-2Decenal, Tridecano, Ácido Hexadecanoico, (Z)-Ciclodeceno, Ácido octadecanoico, Heptadecano, Acetato de (Z)-17Nonadecen-1-ol, Ácido 14- $\beta$-H-Pregna, Ácido carboxílico 1-Fenantreno; dos quais o Undecano, o Acetato de Z-17-Nonadecen1-ol, o Ácido 14- $\beta$-H-Pregna e o Ácido carboxílico 1-fenantreno não estavam presentes nos extratos dos machos.
Enquanto que, os Hexacosano, Octacosano, Tetracosano e Ácido benzenoctanoico 3,4dimetoxi-metil ester foram identificados apenas nos machos.

Fávaro e Zarbin (2012) analisaram duas espécies de percevejos, a saber: Loxa deducta (Walker, 1867) (Hemiptera: Pentatomidae) e Pellaea stictica (Dallas, 1851) (Hemiptera: Pentatomidae); os quais perceberam que no processo de troca de instar, as ninfas transferiram o conteúdo de suas glândulas dorsais para as exúvias. Os compostos químicos identificados nos estádios ninfais das duas espécies foram: (E)-2-Hexenal, (E)-4-(oxo)-2-Hexenal, $(E)$ 2-Octenal, Undecano, (E)-4-(oxo)-2octenal, Dodecano, (E)-2-Decenal, 1Trideceno, Tridecano. O (E)-2-Hexenal estava ausente na espécie $P$. stictica. Nos adultos de $L$. deducta foram encontrados quinze compostos: (E)-2-Hexenal, $(E)$-4(oxo)-2-Hexenal, (E)-2-Octenal, Undecano, (E)-4-(oxo)-2-octenal, Dodecano, (E)-2Decenal, 1-Trideceno, Tridecano, Acetato de $(E)$-2-hexenila, $(E)$-2-Nonenal, Acetato de $(E)$-2-octenila, Tetradecano, Acetato de (E)-2-decenila e Pentadecano. Destes, apenas três $((E)$-2-Decenal, $(E)$-2-Nonenal e Acetato de (E)-2-decenila) não estavam presentes na espécie $P$. stictica.

No estudo das espécies L. deducta e $P$. stictica, descrito no parágrafo acima, as moléculas presentes apenas nos adultos 
foram: Acetato de (E)-2-hexenila, $(E)$-2Nonenal, Acetato de (E)-2-octenila, Tetradecano, Acetato de (E)-2-decenila e Pentadecano. O aldeído (E)-4-(oxo)-2octenal foi encontrado somente nas ninfas. O Tridecano apareceu como composto majoritário seguido de compostos pertencentes aos grupos dos aldeídos, oxoalcenais, ésteres. Os pesquisadores concluíram, também, que a glândula metatorácica, dos pentatomídeos, necessita de alguns dias para se formar completamente, uma vez que está presente, somente, na fase adulta, ou seja, estes artrópodes ainda não são sexualmente maduros com 10 dias de idade adulta (FÁVARO; ZARBIN, 2012).

Fávaro, Santos e Zarbin (2012) pesquisaram os compostos químicos presentes nas exúvias e na glândula metatorácica de outra espécie de pentatomídeo, Agroecus griseus (Dallas, 1851) (Hemiptera: Pentatomidae). O Tridecano foi o composto majoritário dos extratos das exúvias de todos estádios ninfais e da glândula metatorácica dos adultos, seguido do (E)-2-Decenal (1 ${ }^{\circ}$ instar), Tetradecanal ( $2^{\circ}$ ao $5^{\circ}$ instar $)$ e Acetato de (E)-2-metilbutila (adultos). As moléculas identificadas foram: (E)-4-(oxo)2-Hexenal, $(E)$-2-Octenal, Dodecano, $(E)$ 2-Decenal, 1-Trideceno, Tridecano e $(E)$-4(oxo)-2-decenal, nas ninfas de $1^{\circ}$ instar; $(E)$ -
2-Hexenal, (E)-4-(oxo)-2-Hexenal, (E)-2Octenal, Dodecano, 1-Trideceno, Tridecano, e Tetradecanal, nas ninfas de $2^{\circ}$ ao $5^{\circ}$ instar; (E)-2-Hexenal, (E)-4-(oxo)-2Hexenal, (E)-2-Octenal, Dodecano, 1Trideceno, Tridecano, Acetato de (Z)-2metilbutila, Acetato de 3-metil-2-butenila, Acetato de (E)-2-hexenila, Undecano e Acetato de (E)-2-octenila, nos adultos.

\section{Compostos cuticulares}

A cutícula (superfície do corpo) dos insetos é revestida por fina camada específica e impermeável de cera constituída por lipídios, uma mistura de hidrocarbonetos, composta de alcanos e alcenos, lineares e ramificados, de cadeias saturadas e insaturadas com variação de 21 a 70 carbonos. Devido à composição química e a estrutura, a cutícula, funciona como barreira de proteção contra a desidratação e invasão de microrganismo. Alguns fungos e nematoides conseguem ultrapassar essa barreira e atingir a hemocele (cavidade do corpo); mas logo são impedidos pelas proteínas, difenóis, carboidratos, melanina, quitina, regulação da permeabilidade cuticular e realização de movimentos ao atuarem nas articulações (LOCKEY, 1988; FERREIRA, 2012).

Com a evolução dos insetos, surgiu, a função secundária dos hidrocarbonetos, conhecida como feromonal, responsável 
pela comunicação química, intra e interespecífica (HOWARD; BLOMQUIST, 2005), durante breves contatos físicos. Os feromônios realizam um papel significativo no reconhecimento dos indivíduos geneticamente relacionados (BREED; BENNETT, 1987; SINGER; ESPELIE; GAMBOA et al., 1998 JUNGNICKEL et al., 2004). No estudo da avaliação da expressão gênica diferencial e dos hidrocarbonetos cuticulares de rainhas, operárias, machos haplóides e diplóides de Melipona quadrifasciata (HYMENOPTERA: APIDAE), observouse que as substâncias cuticulares produzidas são um reflexo dos genes ativados para sintetizar as enzimas responsáveis pela produção destes compostos, por isso a compreensão da expressão gênica diferencial pode ser auxiliada pela caracterização desses compostos (BORGES, 2011).

Os hidrocarbonetos atuam como feromônios moduladores (provocam mudanças imediatas e reversíveis no comportamento de outro organismo) e desencadeadores (agem em longo prazo no reconhecimento de indivíduos da mesma espécie e na distinção de indivíduos intrusos) de comportamentos e sua ocorrência depende do grupo de insetos, o qual pertence. Como também do gênero e estádio de desenvolvimento em que se encontra (WILSON, 1963; BREED, 1983; SINGER et al. 1998; BLOMQUIST et al., 1998; MONNIN; PEETERS, 1999; SLEDGE et al., 2001; BOOMSMA et al., 2003; NUNES, 2008; BORGE, 2011).

Acredita-se que operárias de formiga da ordem Hymenoptera percebem a atividade ovariana, distinguindo fêmeas férteis de não férteis, por meio do perfil de hidrocarbonetos. (MONNIN; MALOSSE; PEETERS, 1998; MONNIN; MALOSSE, 1999, LIEBIG, 2000; CUVILLIER- HOT et al., 2001; SLEDGE et al., 2001).

Os compostos cuticulares são menos voláteis e, em alguns casos, apresentam alto peso molecular, sendo uma mistura muito complexa de uma variedade de compostos altamente específicos, retidos na superfície do corpo (SANTOS, 2013). Em algumas espécies de insetos, o processo de comunicação se faz principalmente por meio desses hidrocarbonetos de superfície (BREED; BENNETT, 1987, BLOMQUIST et al., 1998, SINGER; ESPELIE; GAMBOA, 1998, HOWARD; BLOMQUIST, 2005, LE CONTE; HEFETZ， 2008, NUNES, 2009, TANNURE-NASCIMENTO;

NASCIMENTO; Z ZUCCHI, 2008; TANNURE-NASCIMENTO et al., 2009). As diferentes combinações qualitativas e quantitativas, dos compostos cuticulares, interferem nas respostas 
comportamentais, as quais dependem da espécie, idade, ou sexo dos insetos (GAMBOA et al., 1986; BLOMQUIST et al., 1998, MONNIN; PEETERS, 1999; SLEDGE et al., 2001; BOOMSMA et al., 2003; ABDALLA et al., 2003); de forma que o perfil químico corresponda uma

\section{REFERÊNCIAS}

ABDALLA, F. C. et al. Comparative study of the cuticular hydrocarbon composition of Melipona bicolor Lepeletier, 1836 (Hymenoptera, Meliponini) workers and queens. Genetics and Molecular Research, v. 2, p. 191-199, 2003.

ACHTEN, W. M. J. et al. Jatropha biodiesel production and use. Biomass and Bioenergy, v. 32, n. 12, p. 1063-1084, 2008.

ALBUQUERQUE, U.P., LUCENA, R.F.P., CUNHA, L.V.F.C. Métodos $e$ técnicas na pesquisa etnobotanica, $2^{\mathrm{a}} \mathrm{ed}$. Comunigraf, Recife, 2008.

AMERICA, C. Jatropha cultivation. Jatropha: a smallholder bioenergy crop. [S.1: s.n.] 2007. v. 8, p. 27-40.

ANDERSSON, M. Sexual selection. Princeton, Princeton University Press, 1994, 599p.

ANDERSSON, M.; IWASA, Y. Sexual selection. Trends in Ecology \& Evolution, vol. 11, p. 53-58, 1996.

ANP (Agência Nacional de Petróleo, Gás Natural e Biocombustíveis). Disponível em: <http://www.anp.gov.br/?pg=73292\& $\mathrm{m}=\& \mathrm{t} 1=\& \mathrm{t} 2=\& \mathrm{t} 3=\& \mathrm{t} 4=\& \mathrm{ar}=\& \mathrm{ps}=\&$ cache bust $=1424178927880 \geq$. Acesso em $18 \mathrm{de}$ fevereiro de 2015. assinatura química individual, de origem endógena e exógena (CARLIN, 1988, revisado por LORENZI; BAGNÈRES; CLÉMENT, 1996), ou seja, os recém emergidos serão influenciados ao longo do tempo pelo contato destes com material do ninho onde se encontram.

ARGENTA, G. et al. Relação da leitura do clorofilômetro com os teores de clorofila extraível e de nitrogênio na folha de milho. Revista Brasileira Fisiologia Vegetal, Londrina, v.13, n.2, p.158-116, 2001.

ARNQVIST, G. Multiple mating in a water strider: mutual benefits or intersexual conflict? Animal Behavior, v. 38, p. 749-756, 1989.

ARRUDA, F. P. et al. Cultivo de pinhão manso (Jatropha curca L.) como alternativo para o semiárido nordestino. Revista Brasileira Oleagenosas e Fibrosas. v. 8, n. 1, p. 789-799, 2004.

AUGUSTUS, G. D. P. S.; JAYABALA, N. M.; SEILERB, G. J. Evaluation and bioinduction of energy components of Jatropha curcas. Biomass and Bioenergy, v. 23, p. 161-164, 2002.

AUSLANE, H. J. Pheromones. In: Capinera, J. L. (Ed.). Encyclopedia of entomology: Springer, 2008, p.2843

AVELAR, R.C. et al. Avaliação da ocorrência do percevejo Pachycoris torridus em plantas de pinhão manso do banco de germoplasma da UFLA. 2007. $5 \mathrm{p}$.

AZAM, M. M.; WARIS, A.; NAHAR, N. $M$. Prospects and potential of fatty acid methyl esters of some non-traditional seed oils for use as biodiesel in India. Biomass and Bioenergy, v. 29, p. 293-302, 2005. 
BAKER, N. R.; ROSENQVIST, E. Applications of chlorophyll fluorescence can improve crop production strategies: an examination of future possibilities. Journal of Experimental Botany, v. 55, n. 403, p. 1607-1621, 2004.

BENETT, C. G. S. et al. Produtividade e composição bromatológica do capimmarandu a fontes e doses de nitrogênio. Ciência Agrotecnologia, Lavras, v. 32, n. 5, p. 1629-1636, set./ out., 2008.

\section{BENVENGA; FERNANDES;}

GRAVENA. Tomada de decisão de controle da traça-do-tomateiro através de armadilhas com feromônio sexual. Horticultura Brasileira, v. 25, p. 164-169, 2007.

BERGMANN, J.; GONZÁLEZ, A.; ZARBIN, P. H. G. Insect Pheromone Research in South America. JOURNAL OF THE BRAZILIAN CHEMICAL SOCIETY. v.20, p.1206-1219, 2009.

BILLEN, J. A importância de glândulas exócrinas na sociedade de insetos. In: VILELA, E. F. et. al. (Eds.). Insetos Sociais: da Biologia à Aplicação. Viçosa: UFV, 2008. p. 87-92.

BIODIESELBR. Disponível em: <http://www.biodieselbr.com/noticias/mate ria-prima/jatropha/empresa-euadesenvolve-jatropha-2-080114.htm>. Acesso em 10 de janeiro de 2015.

BJOSTAD, L. B. Insect eletroantennogram responses to semiochemicals recorded with na inexpensive personal computer.

Physiological Entomology. vol. 13, p. 139145, 1998.

BLATT, S. E. et al. Alarm pheromone system of the western conifer seed bug, Leptoglossus occidentalis. Journal of Chemical Ecology, v. 24, n. 6, 1998.
BLOMQUIST, G. J. et al. The cuticule and cuticular hydrocarbons of insects: structure, function, and biochemistry. In: Pheromone communication in social insect (Vander Meer RK, Breed MD, Winston ML and Espelie KE, eds.). Westview Press, Boulder, 1998, 35- 54 p.

BOOMSMA, J.J. et al. Informational constraints on optimal sex allocation in ants. Proceedings of the National Academy of Sciences (USA), v. 100, p.8799-8804, 2003.

BORGES FILHO, R. da C. et al. Development of Pachycoris torridus (Hemiptera : Scutelleridae ) on Jatropha curcas ( Euphorbiaceae), Psidium cattleianum ( Myrtaceae) and Aleurites fordii ( Euphorbiaceae ). Florida Entomological Society, v. 96, n. 3, p. 1149-1157, 2013.

BORGES, A. A. Avaliação da expressão gênica diferencial e dos hidrocarbonetos cuticulares de rainhas, operárias, machos haplóides e diplóides de Melipona quadrifasciata (HYMENOPTERA: APIDAE). 2011.

BORGES, M. A male-produced sex pheromone from the neotropical redbanded stink bug, Piezodorus guildinii. Journal of Chemical Ecology, v.33, p.1235, 2007.

BORGES, M.; ALDRICH, J. R. Attractant pheromone for nearctic stink bug, Euschistus obscurus (heteroptera: pentatomidae): insight into a neotropical relative. J. of Chem. Ecology, v.20, p.1095-1102, 1994. BREED, M. D. Nestmate recognition in honeybees. Animal Behavior, vol.31, p. 86-91, 1983.

BREED, M. D.; BENNETT, B. Kin recognition in highly eusocial insects. In: FLETCHER, D. J. C., MICHENER, C. D. (Eds.), Kin Recognition in Animals. John Wiley \& Sons, Chichester, p. 243-285, 1987. 
BROGLIO-MICHELETTI, S. M. F. et al. Primeiro registro de Pachycoris torridus (Scopoli , 1772 ). Ciências Agrotécnica, p. 1654-1657, 2010.

CAIRO, P. A. R; et al. Análise de Crescimento de Plantas - Vitória da Conquista: Edições UESB, 2008.

CALBO, A.G.; SILVA, W.L.C., TORRES, A.C. Comparação de modelos e estratégias para análise de crescimento. Revista Brasileira de Fisiologia Vegetal, v.1, n.1, p. 1-18, 1989.

CARLIN, N. F. Discrimination between and within colonies of social insects: Two null hypotheses. Netherlands Journal of Zoology, v. 39, p. 86-100, 1988.

CATUNDA, M.G. et al. Efeitos de herbicidas na atividade fotossintética e no crescimento de abacaxi (Ananas comosus).

Planta Daninha, Viçosa, v.23, n.1, p.115121, 2005.

CHAPMAN, T. et al. Cost of mating in Drosophila melanogaster females is mediated by male accessory gland products. Nature, v. 373, p. 241-244, 1995. CORRÊA, M. J. P.; ALVES, P. L. da C. A. Efeitos da aplicação de herbicidas sobre a eficiência fotoquímica em plantas de soja convencional e geneticamente modificada.

Ciência e Agrotecnologia, v. 34, n. 5, p. 1136-1145, 2010.

COSTA LIMA, A. C. Insetos do Brasil, $2^{\circ}$ tomo, capítulo 22, Hemípteros. Série Didática Núm. 3. Escola Nacional de Agronomia, Rio de Janeiro, 1940, 351p.

COSTA, C. et al. Inter-relationships of applied nitrogen, SPAD, and yield of leafy and non-leafy maize genotypes. Journal of Plant Nutrition, v.24, n.8, p.1173-1194, 2001.
CRUDGINGTON, H. S.; SIVA-JOTHY, M. T. Genital damage, kicking and early death. Nature, v. 407, p. 855-856, 2000.

CUVILLIER- HOT, V. V. et al. Sex, age and ovarian activity affect cuticular hydrocarbons in Diacamma ceylonense, a queenless ant. Journal of Insect Physiology. v. 47, p. 485- 493, 2001.

DRUMMOND, O.A. et al. Cultura do pinhão manso. Belo Horizonte: Epamig, 1984. 99p.

DURAK, D.; KALENDER, Y. Fine structure and chemical analysis of the metathoracic scent gland secretion in Graphosoma lineatum (Linnaeus, 1758) (Heteroptera, Pentatomidae). Comptes rendus biologies, v. 332, n. 1, p. 34-42, 2009.

IEDVARDSSON, M.; ARNQVIST, G. Copulatory courtship and cryptic female choice in red $\mathrm{fl}$ our beetles Tribolium castaneum. Proceedings of the Royal Society of London B, v. 267, p.559-563, 2000.

FÁVARO, C. F.; SANTOS, T. B.; ZARBIN, P. H. G. Defensive compounds and male-produced sex pheromone of the stink bug, Agroecus griseus. Journal of chemical ecology, v. 38, n. 9, p. 1124-32, 2012.

FÁVARO, C. F.; ZARBIN, P. H. G. Identificação dos compostos defensivos encontrados nas glândulas metatorácica e abdominais dorsais dos percevejos Loxa deducta e Pellaea stictica (Heteroptera: Pentatomidae). Quimca Nova, v. 35, n. 8, p. 1582-1586, 2012.

FERREIRA, A. C. Da vespa Mischocyttarus consimilis (Hymenoptera: Vespidae) por cromatografia gasosa. Dourados: Universidade Estadual do Mato Grosso do Sul, 2012. 39p. Dissertação Mestrado. 
FERREIRA, E.; BARRIGOSSI, J. A. F.; VIEIRA, N. R. D. A. Percevejos das panículas do arroz: fauna heteroptera associada ao arroz. Santo Antônio de Goiás, GO: Embrapa Arroz e Feijão. Circular Técnica 43, 2001, 52p.

FORSON, F. K.; ODURO, E. K.; HAMMOND, D. E. Performance of Jatropha oil blends in a diesel engine. Renewable Energy, v. 29, p. 1135-1145, 2004.

FROESCHNER, R.C. Family Scutelleridae Leach. The shield bugs, 1815, p. 684-693. In: T.J. Henry; R.C. Froeschner (eds.), Catalog of the Heteroptera or true bugs, of Canada and the Continental United States. E.J. Brill.,New York, 1988, 958p.

GABRIEL, D. et al. Estudo com o percevejo Pachycoris torridus (Scopoli, 1772) (Hemitera: Scutelleridae) e seu inimigo natural Pseudotelenomus pachycoris (Hymenoptera: Scelionidae) em cultura do pinhão paraguaio Jatropha spp. O Biológico, São Paulo, v.54, n.1/6, p.1720, 1988.

GALLINDO, F. O gênero Jatropha $L$. para Pernambuco. Dissertação de mestrado, Universidade Federal Rural de Pernambuco, Recife, 1985.

GALLO, D. et al. Entomolologia Agrícola. FEALQ, Piracicaba, 2002, 920p.

GAMBOA, J. G. et al. Kin recognition in social wasps: combining chemical and behavioural evidence. Animal Behaviour, v. 51, p. 625- 629, 1996.

GIULIETTI, A. M.; CONCEIÇÃO. A.; QUEIROZ, L. P. (Ed.) Diversidade e caracterização das fanerógamas do SemiÁrido brasileiro. Recife: Associação de Plantas do Nordeste, v. 1, 2006.

GLYNN, P.; FRASER, C.; GILLIAN, A. Foliar salt tolerance of Acer genotypes using chlorophyll fluorescence. Journal Arboriculture, v.29, p.61-65, 2003.

GUNAWARDENA, N. E.; BANDUMATHIE, M. K. Defensive secretion of rice bug, Leptocorisa oratorius Fabricius (Hemiptera : Coreidae): a unique chemical combination and its toxic, repellent, a $\mathrm{n} \mathrm{d}$ alarm properties. Journal of Chemical Ecology, v. 19, n. 4, p. 851-861, 1993.

HERNDON, L. A.; WOLFNER, M. F. A Drosophila seminal fluid protein, Acp26Aa, stimulates egg laying in females for 1 day after mating. Proc Natl Acad Sci USA, vol. 92, p. 10114-10118, 1995.

HÖLLDOBLER, B.; CARLIN, N. F. Anonymity and specificity in the chemical communication signals of social insects. Journal of Comparative Physiology, v. 161A, p. 567-581, 1987.

HOWARD, R. W.; BLOMQUIST, G. J. Ecological, behavioral, and biochemical aspects of insect hydrocarbons. Annual Review of Entomology, vol. 50, p. 371393, 2005.

JAHNKE, S. M.; REDAELLI, L. R.; SANTOS, R. S. S. Dos. Caracterização morfológica dos órgãos internos de reprodução Coreidae) em diferentes idades. Arquivos do Instituto Biológico, v. 78, n. 1, p. 31-35, 2011.

JUNGNICKEL, H. et al. Chemical basis for inter-colonial aggression in the stingless bees Scraptotrigona bipunctata (Hymenptera: Apidae). Journal Insect Physiology, v. 50, p. 761-766, 2004.

KAWADA, H; KITAMURA, C. The reproductive behavior of the brown marmorated stink bug, Halyomorpha mista UHLER (Heteroptera: Pentatomidae). Applied Entomology and Zoology, v.18, p.234-242, 1983. 
KIM, H.; LEE, J.-H. Phenology Simulation Model of Scotinophara lurida (Hemiptera: Pentatomidae). Environmental Entomology, v.37, p.660-669, 2008.

KIVAN, M. Effects of azadirachtin on the sunn pest, Eurygaster integriceps put. (heteroptera, scutelleridae) in the laboratory. Journal of Central European Agriculture, v.6, p.157-160, 2005.

KOCHEVA, K. et al. Evaluation of chlorophyll fluorescence and membrane injury in the leaves of barley cultivars under osmotic stress. Bioelectrochemistry, n. 63, p. 121-124, 2004.

KOSHIYAMA, Y. et al. Nutritional contribution to females of 14C-labeled male secretions transferred during mating in Menida scotti (Heteroptera: Pentatomidae). Res Popul Ecol, vol. 38, p. 51-56, 1996.

KRALL, B. S. et al. CHEMICAL DEFENSE IN THE STINK BUG Cosmopepla bimaculata. Journal of Chemical Ecology, v. 25, n. 11, p. 24772494, 1999.

KRAMER, P. J. Water relations of plants. New York: Academic Press, 1983. 489p.

KRAUSE, G. H.; WEIS, E. Chlorophyll fluorescence and photosynthesis: The basics. Annual Review of Plant Physiology and Plant Molecular Biology, Palo Alto, v.42, p.313-349, 1991.

LARCHER, W. Ecofiosiologia vegetal. São Carlos: Rima, 2004. 531 p.

LAUMANN, R. A. et al. Metodologia para estudos de semioquímicos e a sua aplicação no manejo de pragas. A influência de voláteis de soja no comportamento do parasitóide Telenomus podisi. Circular Técnica, Embrapa, n. 24, agosto, p. 1-6, 2003.
LE CONTE, Y.; HEFETZ, A. Primer pheromones in social hymenoptera. Annual Review of Entomology, v. 53, p. 523-542, 2008.

LEAL, W. S.; PANIZZI, A. R.; NIVA, C. C. Alarm pheromone system of leaf-footed bug Leptoglossus zonatus (Heteroptera : Coreidae). Journal of Chemical Ecology, v. 20, n. 5, p. 1209-1216, 1994.

LENS. Disponível em: $<$ https://www.lens.org/lens/search?n=10\& $\mathrm{q}=$ jatropha+curcas $\& \mathrm{v}=$ analysis $\& \mathrm{p}=0 \& \mathrm{f}=\mathrm{tr}$ ue\#f/type >. Acesso em 28 de agosto de 2015.

LIANG, Y. et al. Responses of Jatropha curcas seedlings to cold stress: photosynthesis - related proteins and chlorophyll fluorescence characteristics. Physiologia Plantarum, n. 131, p. 508517. 2007.

LIEBIG, J. Are variations in cuticular hydrocarbons of queens and workers a reliable signal of fertility in the ant Harpegnathos saltator? Proceedings of the National Academy of Sciences USA, vol. 97, p. $4124-4131,2000$.

LIMA, E.R.; DELLA LUCIA, T.M.C. "Biodinâmica dos Feromônios In:Vilela, E.F., Della Lucia (eds.), Feromônios de Insetos, Biologia, química e emprego no manejo de pragas", São Paulo, Holos Editora, 2001 p. 13-26.

LOCKEY, K.H. Lipids of the insect cuticle: origin, composition and function. Comparative Biochemistry and Physiology $B$, v. 89, p. 595-645, 1988.

LORENZI, M. C.; BAGNÈRES, A. G.; CLÉMENT, J. L. The role of cuticular hydrocarbons in social insects: is it the same in paper wasps? In: TURILLAZZI, S. \& WEST-EBERHARD, M. J. (eds.) Natural History and Evolution of Paper 
Wasps, Oxford University Press, UK, p. 178-189, 1996.

MACHADO, E.C. et al. Índices biométricos de duas cultivares de cana-deaçúcar. Pesquisa Agropecuária Brasileira, v.17, n.9, p1323-1329, 1982.

MAGNHAGEN, C. Predation risk as a cost of repro- duction. Trends of Ecologiy \& Evolution, v.6, p.183-186, 1991.

MARENCO, R. A. et al. Fotoinibição dinâmica da fotossíntese em árvores de dossel da Amazônia Central, Revista Brasileira de Biociências, v. 5, p. 150-152, 2007.

MARENCO, R.A.; LOPES, N.F. Fisiologia Vegetal: Fotossíntese, respiração, relações hídricas e nutrição mineral, Editora UFV. Viçosa, MG. 2005, 451p.

MARQUES, F. A. et al. Identification of Defensive Compounds in Metathoracic Glands of Adults of the Stink Bug Dichelops melacanthus (Hemiptera: Pentatomidae). Journal of the Brazilian Chemical Society, v. 18, n. 6, p. 12421246, 2007.

MAXWELL, K.; JOHNSON, G.N. Chlorophyll fluorescence: a pratical guide. Journal of Experimental Botany, v. 51, p. 659-668, 2000.

MCNEIL, J. N. Behavio ral ecology of pheromone-mediated communication in moths and its importance in the use of pheromone traps. Annual Review of Entomology, v.36, p.407-430, 1991.

MCPHERSON, J. E., MCPHERSON, R. M. Stink bugs of economic importance in America north of Mexico, CRC Press, 2000, 272p.

MICHELOTTO, M.D.; SILVA, R.A. da; BUSOLI, A.C. Percevejos (Hemiptera:
Heteroptera) coletados em aceroleira (Malpighia glabra L.) em Jaboticabal, SP. Arquivos do Instituto Biológico, São Paulo, v.73, n.1, p.123-125, 2006.

MILLAR, J. G. et al. Pentatomid bug pheromones in IPM: possible applications and limitations. IOBC Bulletin, v.25, n.9, p.241-250, 2002.

MONNIN, T.; MALOSSE, C.; PEETERS, C. Solid- phase microextration and cuticular hydrocarbon differences related to reproductive activity in queenless ant Dinoponera quadriceps. Journal of Chemical Ecology, vol. 24, p. 473 - 490, 1998.

MONNIN, T.; PEETERS, C. Dominance hierarchy and reproductive conflicts among subordinates in a monogynous queenless ant. Behavioral Ecology, v. 10, p. $23-32,1999$.

MONTE, O. Algumas variações nos desenhos e cores de Pachycoris torridus (Scopoli). O Campo, n. Janeiro, p. 71, 1937.

NAVA, D. E.; DELMAR, S. Insetos Praga e Benéficos na Cultura do Tungue.

Embrapa Clima Temperado. 1. ed. Pelotas: Embrapa, n. 276, 2009. 13 p.

NUNES, T. M. Cuticular hydrocarbons in the stingless bee Schwarziana quadripunctata (Hymenoptera, Apidae, Meliponini): differences between colonies, castes and age. Genetics and Molecular Research, v. 8, p. 589-595, 2009.

NUNES, T. M. Nestmate recognition in a stingless bee: does the similarity of chemical cues determine guard acceptance? Animal Behaviour, v. 75, p. 1165-1171, 2008.

OGREN, E.; OQUIST, G. Effect of drought on photosynthesis, chlorophyll florescence and photoinhibition 
susceptibility in intact willow leaves. Planta, Berlin, v.166, n.3, p.380-388, 1985.

OLIVEIRA, H. N. De; SILVA, C. J. Da. Artrópodes Benéficos na Cultura do Pinhão-Manso em Mato Grosso do Sul. Embrapa, n. 1, p. 1-4, 2011.

OPENSHAW, K. A review of Jatrop ha curcas: an oil plant of unfulfilled promise. Biomass and Bioenergy, Amsterdam, v.19, p.1-15, 2000.

OSANAI, M.; CHEN, P. S. A comparative study on the arginine degradation cascade for sperm maturation of Bombyx mori and Drosophila melanogaster. Amino Acids, vol. 5, p. 341-350, 1993.

PAIVA, M. R.; PEDROSA-MACEDO, J. H. Feromonas de Insetos. Curitiba: Ctgtz, 1985. $84 \mathrm{p}$.

PANIZZI, A. R. Wild Hosts of Pentatomids:Ecological Significance and Role in Their Pest Status on Crops. Annual Review Entomology., v.42, p.99-122, 1977.

PAREJA, M. et al. Inter- and intraspecific variation in defensive compounds produced by five neotropical stink bug species (Hemiptera: Pentatomidae). Journal of insect physiology, v. 53, n. 7, p. 639-48, 2007.

PARK, K. C. et al. Odor discrimination using insect eletroantennogram responses from an insect antennal array. Chemical Senses, Oxford, V. 27, p. 343-352, 2002.

PAVIS, C. et al. Dorsal abdominal glands in nymphs of southern green stink bug, Nezara viridula (L .) ( Heteroptera:

Pentatomidae ): chemistry of secretions of five instars and role of ( E ) -4-oxo-2decenal, compound specific to first instars. Journal of Chemical Ecology, n. 9, p. 2213-2227, 1994.

\section{PORTAL PERIÓDICOS DA CAPES.}

Disponível em:

$<$ http://www.periodicos.capes.gov.br/index .php?option=com_pmetabusca\&mn $=88 \&$ s $\mathrm{mn}=88 \&$ type $=\mathrm{m} \&$ metali $\mathrm{b}=\mathrm{aHR} 0 \mathrm{cDovL} 21$ scGx1cy5ob3N0ZWQuZXhsaWJyaXNnc m91cC5jb20vcHJpbW9fbGlicmFyeS9saW J3ZWIvYWN0aW9uL3NIYXJjaC5kbz92a WQ9Q0FQRVM=\&Itemid=119>. Acesso em 28 de agosto de 2015.

PEARCY, R.W. et al: Plant Physiological Ecology. Field Methods and Instrumentation, 1991.

PIKART, T. G. et al. New chromatic pattern and fi rst register of Pachycoris torridus damaging Coffea arabica fruits in Viçosa, Minas Gerais State, Brazil (Hemiptera: Scutelleridae). Entomologia Generalis, vol. 33, p. 207-211, 2011.

PIRES, C. S. S. et al. Potencial de uso de armadilhas iscadas com o feromônio sexual do percevejo marrom, Euschistus heros (Heteroptera : Pentatomidae), para o monitoramento populacional de percevejos praga da soja. Manejo Integrado de Plagas y Agroecología (Costa Rica), v. 77, p. 7077, 2006.

PURCINO, A. A. C.; DRUMMOND, O.A. Pinhão manso. Belo Horizonte: EPAMIG, 1986. $7 \mathrm{p}$

REYNOLDS, J. D. Animal breeding systems. Trends in Ecology \& Evolution, vol. 11, p. 68-72, 1996.

RIDLEY, M. The control and frequency of mating in insects. Functional Ecology, vol. 4, p. 75-84, 1990.

RODRIGUES I, S. R. et al. Aspectos biológicos e danos de Pachycoris torridus em pinhão - manso. Bragantia, v. 70, n. 2, p. 356-360, 2011.

RODRIGUES II, M. A. C. de M. Biologia e ecologia química de percevejos 
neotropicais (Heteroptera: Pentatomidae, Coreidae). 2011.

RODRIGUES, A. R. S. et al. Podisus nigrispinus Requer Cópulas Longas para o Sucesso Reprodutivo. Neotropical Entomology 3, v. 38, n. 6, p. 746-753, 2009.

RODRIGUES, A. R. S. et al.

Spermatogenesis, changes in reproductive structures, and time constraint associated with insemination in Podisus nigrispinus. Journal of Insect Pysiology, vol. 54, p. 1543-1551, 2008.

ROLFF, J.; SIVA-JOTHY, M. T.

Copulation corrupts immunity: a mechanism for a cost of mating in insects. Proceedings of the National Academy of Sciences USA, vol. 99, p. 9916-9918, 2002.

ROZANE, D. E. et al. Influência do cultivar, do tipo de folha e do tempo de cultivo na medida indireta da clorofila (SPAD) em mudas de goiabeira. Ciência Agrotecnologia, Lavras, v. 33, n. 6, p. 1538-1543, Nov./dez., 2009.

RYNE, C. Homosexual interactions in bed bugs: alarm pheromones as male recognition signals. Animal Behaviour, v. 78, n. 6, p. 1471-1475, 2009.

SAMPAIO, E.V.S.B. Overview of the Brazilian caatinga. In Seasonally dry tropical forest (S.H. Bullock, H.A. Mooney \& E. Medina, eds.). Cambridge University Press, Cambridge, p.35-63, 1995.

SÁNCHEZ-SOTO, S.; MILANO, P.; NAKANO, O. Nova planta hospedeira e novos padrões cromáticos de Pachycoris torridus (Scopoli) (Hemiptera:

Scutelleridae) no Brasil. Neotropical Entomology, Londrina, v.33, n.1, p.109111, 2004.

SANCHEZ-SOTO, S.; NAKANO, O. Ocorrência de Pachycoris torridus
(Scopoli) (Hemiptera: Scutel- leridae) em acerola (Malpighia glabra L.) no Brasil. Neotropical Entomology, vol. 31, p. 481482, 2002.

SANTOS, C.M. Fenologia e capacidade fotossintética do pinhão-manso (Jatropha curcas L.), 2008.

SANTOS, D. C. de J. Divisão de trabalho e sua relação com a dinâmica dos hidrocarbonetos cuticulares em Melipona scutellaris Divisão de trabalho e sua relação com a dinâmica dos hidrocarbonetos cuticulares em Melipona scutellaris (Hymenoptera, Apidae, Meliponini ). 2013.

SANTOS, J. C. et al. Ecology and behavior of Pachycoris torridus (Hemiptera: Scutelleridae): new host plant, color polymorphism, maternal care and parasitism. Lundiana, v. 6, n. 2, p. 107111, 2005.

SATURNINO, H.M. et al. Cultura do pinhão manso (Jatropha curcas L.). Informe Agropecuário, Belo Horizonte, v.26, n.229, p.44-78, 2005.

SCHAEFER,C.W.; PANIZZI, A. R. Economic importance of Heteroptera: a general view, CRC Press, p.3-8, 2000. SCHOWALTER, T. D. Insect ecology: an ecosystem approach. San Diego, California, USA: Elsevier, 2006, 471 p.

SEVERINO, L. S. et al. Viagem á Índia para Prospecção de Tecnologias sobre Mamona e Pinhão Manso. Campina Grande: Embrapa do algodão. Documento $153,2006.56$ p.

SILVA, A. G. A. et al. Quarto catálogo dos insetos que vivem nas plantas do Brasil. Seus parasitos e predadores. Parte 2, tomo $1^{\circ}$, insetos, hospedeiros e inimigos naturais. Ministério da Agricultura, Rio de Janeiro, 1968, 622p. 
SILVA, P.H.S. Ocorrência de Pachycoris torridus (Scopoli) (Hemiptera:

Scutelleridae) na cultura do pinhão manso Jatropha curcas L. no estado do Piauí, Brasil. Brasília: Embrapa, 2007.

SILVEIRA, P.M.; BRAZ, A.J.B.P.; DIDONET, A.D. Uso do clorofilômetro como indicador da necessidade de adubação nitrogenada no feijoeiro. Pesquisa Agropecuária Brasileira,

Brasília, v.38, n.9, p.1083-1087, 2003. SILVERSTEIN, R. M.; YOUNG, J. C. Insects generally use multicomponent pheromones. In: Beroza, M. (Ed.). Pest Manage-ment with Insect Sex Attractants and Other Behavior-Controlling Chemicals. Washington, D. C.: ACS Symp. series 23, 1976. p. 1-29.

SINGER, T. L.; ESPELIE, K. E.; GAMBOA, G. J. Nest and nestmate discrimination in independent-founding wasps. In: VANDER MEER, R. K.; BREED, M. D.; WINSTON, M. L. \& ESPELIE, E. K. (Eds.), Pheromone Communication in Social Insects. Westview, Boulder, pp. 57-78, 1998.

SINGH, O. P.; SINGH, K. J.; THAKUR, R. D. Studies on the bionomics and chemical control of stink bug, Piezodorus rubrofasciatus Fabricius, a new pest of soybean in Madhya Pradesh. Indian Journal of Plant Protection, v.17, p.81-93, 1989.

SLEDGE, M. F. et al. Recognition of social parasites as nest-mates: adoption of colony- specific host cuticular odours by the paper wasp parasite Polistes sulcifer, 2001.

SOUSA-SOUTO, L. et al. Sperm depletion: a cost for single mated females of Podisus nigrispinus (Dallas, 1851) (Heteroptera: Pentatomidae). Brazilian Archives of Biology and Technology, vol. 49, p. 923-926, 2006.
SOUZA, G. K. et al. Color polymorphism in Pachycoris torridus (Hemiptera: Scutelleridae) and its taxonomic implications. Revista Chilena de História Natural, vol. 85, n. 3, p. 357-359, 2012.

SUAREZ, P. A. Z.; MENEGUETTI, S. M. P.; FERREIRA, V. F. O biodiesel e a política de C \& T brasileira. Química Nova, vol. 29, p.157-1157, 2006.

SUCKLING, D. M. Issues affecting the use of Pheromones and Other Semiochemicals in orchards. Crop protection, v.19, p.677-683, 2000.

TADLER, A., NEMESCHKAL, H. L., PASS, G. Selection of male traits during and after copulation in the seedbug Lygaeus simulans (Heteroptera, Lygaeidae). Biological Journal of the Linnean Society, vol. 68, p. 471-483, 1999.

TAIZ, L.; ZEIGER, E. Fisiologia vegetal. Porto Alegre: Artmed, 2004, 719 p.

TANNURE-NASCIMENTO, I. C.; NASCIMENTO, F. S.; ZUCCHI, R. The look of royalty: visual and odour signals of reproductive status in a paper wasp. Proceedings of the Royal Society of London B, v. 275, p. 2555-2561, 2008. TANNURE-NASCIMENTO, I. C. et al. Decision rules for egg recognition are related to functional roles and chemical cues in the queenless ant Dinoponera quadriceps. Naturwissenschaften, v. 96, p. 857-861, 2009.

TATAGIBA, S. D.; PEZZOPANE, J. E. M. Cinética de emissão de fluorescência das clorofilas em dois clones de eucalyptus. Revista Científica Eletrônica de Engenharia Florestal, n. 10, 2007.

TEGONI, M. et al. Structural aspects of sexual attraction and chemical communication in insects. Trends in 
Biochemical Sciences, vol. 29, p. 257-264, 2004.

THORNHILL, R., ALCOCK, J. The evolution of insect mating systems. Cambridge, Harvard University Press, 1983, 547p.

TIWARI, A.K.; KUMAR, A.; RAHEMAN, H. Biodiesel production from Jatropha oil (Jatropha Curcas) with high free fatty acids: an optimized process. Biomass and Bioenergy, vol. 31, p. 569575, 2007.

TORRES, J. B.; ZANUNCIO, J. C.; OLIVEIRA, M. C. Mating frequency and its effect on female reproductive output in the stinkbug predator Podisus nigrispinus (Heteroptera: Pentatomidae). Med Fac Landbouww Univ Gent, vol. 62, p. 491498, 1997.

TRAM, U.; WOLFNER, M. F. Male seminal fl uid proteins are essential for sperm storage in Drosophila melanogaster. Genetics, vol. 153, p. 837-844, 1999.

TREGENZA, T., WEDELL, N.

Polyandrous females avoid cost of inbreeding. Nature, vol. 415, p. 71-73, 2002.

TREMATERRA, P. Pheromones and Integrated Pest Management in stored products. IOBC Bulletin, v.25, n.3, p.9-14, 2002.

TROVÃO, D. M. B. et al. Variações sazonais de aspectos fisiológicos de espécies da Caatinga. Revista Brasileira de Engenharia Agrícola Ambiental, v. 11, n. 3, p. 307-311, 2007.

WANDERLEY FILHO, H. C. D. L. Uso de bioestimulantes e enraizadores no crescimento inicial e tolerância à seca em cana-de-açúcar. 2011.
WEBSTER, G.L. Synopsis of the genera and suprageneric taxa of Euphorbiaceae. Annals of the Missouri Botanical Garden, vol. 81, p. 33-144, 1994.

WILSON, E. Pheromones. Scientific American. Vol. 208, p. 100- 114, 1963.

WORLD HEALTH ORGANIZATION. Public health impact of pesticides used in agriculture. World Health Organization, Geneva, 1990.

ZANANDRE, A. I. et al. Efeito da salinidade sob parâmetros de fluorescência em Phaseolus vulgaris. Revista Brasileira de Agrociência, v. 12, n. 2, p. 157-161, 2006.

ZARBIN, P. H. G. et al. Alarm Pheromone System of Stink Bug Piezodorus guildinii (Heteroptera : Pentatomidae). Journal of Chemical Ecology, v. 11, n. 4, p. 424-428, 2000.

ZARBIN, P. H. G.; RODRIGUES, M. A. C. M.; LIMA, E. R. Feromônios de insetos: tecnologia e desafios para uma agricultura competitiva no brasil. Química Nova, v. 32, n. 3, p. 722-731, 2009.

ZEH, J. A.; ZEH, D. W. The evolution of polyandry I: Intragenomic confl ict and genetic and genetic incompatibility. Proceedings of the Royal Society of London B, vol. 263, p. 1711-1717, 1996.

ZOTARELLI, L. et al. Calibração do medidor de clorofila SPAD-502 para avaliação do conteúdo de nitrogênio do milho. Pesquisa Agropecuária Brasileira, Brasília, v.38, n.9, p.1117-1192, 2003. ŽUNIČ, A. et al. Communication with signals produced by abdominal vibration, tremulation, and percussion in Podisus maculiventris (Heteroptera: Pentatomidae). Annals of the Entomological Society of America, vol. 101, p. 1169-1178, 2008. 